\title{
LAS REMESAS AMERICANAS \\ EN LAS FINANZAS DE LA REAL HACIENDA. \\ LA CUANTIFICACIÓN DEL DINERO \\ DE LA CORONA (1621-1675) *
}

\section{CARLOS ÁLVAREZ NOGAL}

Universidad de Sevilla

\section{RESUMEN}

A la hora de estudiar la cuantificación de las remesas americanas se suele distinguir entre caudales públicos y privados, pero de esta ambigua clasificación sólo se obtienen resultados inexactos, especialmente en el siglo xvir. Este trabajo estudia los metales preciosos llegados para la Real Hacienda entre 1621 y 1675, y pretende mostrar que las remesas con que contó la Corona durante ese período fueron más importantes de lo que tradicionalmente se ha considerado. La causa de su infravaloración reside en un equivocado análisis de la fuente de carácter oficial utilizada en los estudios precedentes. La importancia de cuantificar lo más exactamente posible el volumen de metales preciosos con que contó la Real Hacienda sirve para entender mejor las relaciones de la Corona con los banqueros extranjeros.

\section{ABSTRACT}

The quantification of the American remittances is tended to distinguish among wealth public and private. Fruit of this are some wrong results, above all in the XVII century. The present article study the precious metals import for the Royal Estate. It is intended to show that the remittances with which

* Este trabajo y sus conclusiones son fruto de la investigación sobre un tema más amplio relacionado con los metales preciosos americanos y las finanzas públicas del reinado de Felipe IV, para la cual hemos contado con la ayuda económica de la Junta de Andalucía y del Ministerio de Educación y Cultura, dentro del proyecto de Investigación «Relaciones de poder y comercio colonial. Sevilla y Cádiz como modelos» (PS95-0008) financiado por la DGYCIT. 
counted the Wreath were more important than what traditionally it has been considered. The cause of its infravaloration resides in a wrong analysis of the source of used official character. To know which was the volume of precious metals with which counted the Royal Estate is a resolutive topic to understand the evolution of the credit of the $W$ reath and the relationships that maintained with the foreign bankers.

\section{INTRODUCCIÓN}

El interés que siempre ha existido por saber la cantidad exacta de metales preciosos americanos que llegó a Europa ha generado una gran cantidad de cifras, de las que la mayoría no son más que meras especulaciones '. E. J. Hamilton abordó el tema con un talante científico y sentó las bases de lo que a partir de entonces sería la base estadística aceptada y discutida ${ }^{2}$. Su principal objetivo era cuantificar las remesas llegadas en las flotas para poder así observar sus efectos en la economía europea y, sobre todo, las repercusiones de esas importaciones en el alza de los precios y salarios. No pretendía estudiar los metales preciosos en sí mismos, sino sólo su influencia en un marco económico más amplio. Ése fue el motivo por el que no profundizó en los problemas planteados en la llegada de esos fondos, ni en el especial tratamiento que recibieron los metales preciosos al ser manipulados por los oficiales reales. Sin embargo, Hamilton hizo una importante distinción entre caudales públicos y privados a la hora de exponer sus cifras, que sentó las bases de cualquier discusión al respecto y sobre la cual se han seguido construyendo las series estadísticas. Los criterios de esa clasificación son muy discutibles en el siglo XVII, cuando la manipulación de los metales preciosos adquirió una complejidad tal que se trastocaron muchos de los mecanismos que habían sido utilizados hasta entonces para controlar oficialmente el recibo de las remesas. Algo que trataremos de explicar en estas páginas.

La polémica en torno a la cuantificación de los metales preciosos ha girado siempre en torno a los intentos por aportar cifras ajustadas del stock de metales llegados en las flotas. En este marco y como exponentes de

${ }^{1}$ El propio Vilar (1974, p. 107, nota 4), señala cómo los primeros trabajos eran tan imperfectos que primero Lexis y después Haring redujeron a la mitad algunas de esas estimaciones, Haring (1915). Una recopilación de esos trabajos se puede consultar en Bernal (1997), pp. 10-14.

${ }^{2}$ Hamilton (1928 y 1929a y b) publicó sus primeros resultados en varios artículos y después fueron reunidos, completados y publicados en 1934. De ese último trabajo existe una tradución española en Hamilton (1975). 
esa discusión, encontramos las opiniones de Hamilton y la posterior revisión de Morineau ${ }^{3}$. Junto a ellos, disponemos también de toda una serie de investigaciones destinadas a completar las series ${ }^{4}$. La polémica suscitada sigue abierta, ante la imposibilidad de ponerse de acuerdo en cuanto a las cifras llegadas para particulares, debido al incremento del fraude en el siglo XVII.

Estas páginas pretenden avanzar en un aspecto de las remesas americanas al que hasta ahora apenas se le había prestado suficiente atención, siguiendo planteamientos propios de la tradicional discusión planteada en torno a la llegada de metales preciosos. No se trata de cuantificar la masa total de metales preciosos llegados a la Península Ibérica, sino de saber el valor de los que llegaron a disposición de la Real Hacienda en la etapa central del siglo XVII, con el objetivo de poder establecer después algún tipo de relación entre ese volumen y la capacidad de endeudamiento a corto plazo de la Monarquía. Algunos investigadores ya habían señalado la necesidad de abordar este tema con profundidad. Pierre Vilar señaló hace tiempo la importancia internacional que tenían los fondos llegados para el rey, porque eran los que más rápidamente se repartían por Europa debido a las deudas del soberano. Según este autor, para comprender mejor esas operaciones financieras, primero era necesario empezar examinando la relación de las llegadas de oro y plata con el tesoro público, para después abordar en mejores condiciones un análisis de los lazos de unión entre el tesoro público y los financieros internacionales ${ }^{5}$. Los resultados de esta investigación se insertan en el intento por llevar a cabo un estudio más

${ }^{3}$ Morineau (1969, 1970 y 1985). Recientemente García-Baquero (1996) ha llevado a cabo una revisión de las cantidades para el siglo XvIII, utilizando como fuente fundamental no las relaciones sumarias, sino los libros registros de cada navio. Este artículo aclara muchas cuestiones, hasta ahora confusas, permitiendo entender mejor los principales aspectos de la polémica surgida en torno a la cuantificación.

4 Los trabajos de Laiglesia (1904) y Haring (1915) descalificaban las noticias publicadas hasta entonces sin base documental. Domínguez Ortiz (1969) y Serrano Mangas (1989) coinciden más o menos con las cifras de Hamilton, pues también ellos utilizan las relaciones sumarias. Chaunu (1955-60) y García Fuentes (1980) estudian los metales preciosos como una mercancía más tampoco abordan en profundidad la titularidad de esas partidas. Sus cifras confirman la tendencia ya señalada en la evolución de las cantidades. Junto a este esfuerzo, también ha habido un intento serio por clarificar las cifras desde la óptica americana. Disponemos del estudio de las cajas reales de Tepaske y Klein (1982) y del trabajo de Bancora Cañedo (1959) sobre las cartas-cuentas de los oficiales reales de Lima. Este último trabajo presenta las cantidades agrupadas bajo el título de Real Hacienda y se puede suponer que están incluidas en ellas los caudales de «Cruzada» y «Donativo». La segunda mitad del xvi fue completada por Rodríguez Vicente (1964). En esta misma línea se encuadra el trabajo de Ruiz Rivera (1977) sobre el Nuevo Reino de Granada.

${ }^{5}$ Vilar (1972), p. 198. 
exhaustivo de los caudales públicos americanos, en torno al primero de los temas planteados por Vilar. Se trata de abordar el estudio de los metales preciosos desde la óptica de la Real Hacienda, con el objetivo de precisar algunas cuestiones en torno a la cuantificación de las cantidades llegadas para el rey, que sirvan de base para después estudiar mejor el papel que tuvieron esos fondos en la negociación del crédito de la Monarquía. En el fondo, clarificar algunas cuestiones vinculadas con la llegada de las remesas de carácter público, aportando una cuantificación más ajustada.

$\mathrm{El}$ interés por precisar con mayor rigor esa cifra responde al hecho de que esos fondos contribuyeron muy directamente a la financiación de la política de la Corona ${ }^{6}$. Las cifras de Hamilton tanto públicas como privadas evolucionan a la baja a lo largo del xvn. Sin embargo, a partir de 1621, y por las ambiciones políticas del nuevo monarca, fue necesario aumentar considerablemente los presupuestos. Una parte de ese creciente gasto se sostuvo gracias al incremento de la presión fiscal, y cuando ese recurso no fue suficiente se recurrió a la solicitud de donativos. En cualquier caso, el presupuesto se sostenía siempre gracias al crédito de los banqueros internacionales, sin los cuales era casi imposible cumplir con puntualidad los pagos, algo tan negativo o más que la insuficiencia de los ingresos. Es precisamente en este punto, en las relaciones de la Monarquía con la banca, donde las remesas americanas jugaban un papel esencial, difícilmente sustituible por otro tipo de ingreso.

Es indudable que los metales preciosos americanos no fueron los únicos y ni siquiera la parte más cuantiosa de los ingresos que sostenían el crédito de la Monarquía. Sin embargo, las remesas americanas tenían unas características que las hacían especialmente atractivas a los grandes banqueros de ámbito internacional. Por ejemplo, de poco servía tener la seguridad de que en el plazo de dos o tres años la Real Hacienda era capaz de recaudar millones de ducados en diferentes rentas, si al aproximarse la fecha de una feria de pagos en Italia, el lugar donde habitualmente se entretenían los débitos de la Corona con sus banqueros, los oficiales reales no eran capaces de entregar dinero líquido para cancelar al menos una parte de esa deuda. No nos podemos olvidar de que los banqueros que prestaban al Rey de España eran, a su vez, deudores de otras muchas personas y de otros banqueros. Su negocio se mantenía gracias a la confianza que despertaba la puntual atención de sus compromisos de pago. El prestigio de la Monarquía Hispánica y su patente riqueza a

\footnotetext{
${ }^{6}$ Martín Acosta (1992), Álvarez Nogal (1997a).
} 
los ojos de toda Europa, le permitían contar con más crédito y también con más tiempo, a la hora de cancelar sus deudas, pero eso no la eximía de contar con liquidez al vencer los plazos. Pues bien, esa liquidez que a veces era absolutamente imprescindible para continuar negociando con la banca extranjera, se la ofrecían las remesas americanas de una forma no comparable a ningún otro tipo de ingreso. Esa importancia de los metales preciosos también explica los continuos secuestros de dinero a los particulares en el momento de llegar las flotas y galeones, a pesar del gran perjuicio que esta medida causaba al registro obligatorio, y por lo tanto a todo el sistema de flotas.

Todos estos factores importaban mucho a la hora de negociar nuevos créditos, y por lo tanto el aumento de las remesas americanas a disposición del Consejo mejoraba la posición negociadora de éste con respecto a los agentes financieros, independientemente de la proporción que la cuantía de las remesas públicas tuviese con el resto de los ingresos de la Real Hacienda. Así por ejemplo, tal y como señala Domínguez Ortiz, las rentas ordinarias tenían en 1621 un valor de 5.216 .000 ducados anuales, pero Felipe III «todas las dejó ocupadas y situadas aún en mayor cantidad» ${ }^{7}$, lo cual significaba que aunque se tratase de ingresos de la Real Hacienda, en realidad ésta ya no era dueña de ese dinero, al estar comprometido en el pago de deudas atrasadas.

Por su parte, este mismo autor ha puesto de manifiesto la mayor disposición presupuestaria existente en los primeros años del reinado de Felipe IV. En 1626 las provisiones de los banqueros suponían 5.980 .000 ducados y escudos, en 1634 fueron 7.256 .000 escudos, y en 1637 se pretendía alcanzar los 11 millones ${ }^{8}$. Por el contrario, las series de que disponemos para la llegada de caudales americanos de carácter público expresan un descenso progresivo de ese tipo de recursos a partir de 1621, precisamente uno de los elementos clave a la hora de negociar nuevos créditos con los banqueros. La pregunta surge entonces con facilidad. ¿Cómo fue capaz la Monarquía de sostener sus finanzas, atraer a los principales banqueros europeos, convirtiéndolos en sus clientes, y sostener los elevados costes del crédito a corto plazo, en un siglo en el que progresivamente disminuía la parte cualitativamente más importante de sus ingresos? Era necesario estudiar de nuevo y en profundidad la cuantificación de las remesas americanas de carácter público, quizá así seamos capaces de dar respuesta

${ }^{7}$ Domínguez Ortiz (1960), apéndice I, pp. 313.

${ }^{8}$ Domínguez Ortiz (1960), pp. 19-47. 
a esta pregunta. Además, junto a esa «aparente» disminución de las remesas avalada por los estudios realizados sobre la cuantificación de los metales preciosos, el contexto económico fue tremendamente adverso en el siglo XVII, por las perturbaciones monetarias del cobre, la decadencia del sistema productivo y los conflictos regionales de la Península Ibérica. Sin embargo, una explicación de la capacidad política y financiera desplegada por la Monarquía Hispánica, en lo que tradicionalmente se ha considerado un siglo de crisis, se puede encontrar entendiendo bien el papel que jugaron los metales preciosos dentro de sus finanzas. Por tanto, conviene saber realmente y con precisión cuál fue la cantidad manejada por la Real Hacienda.

Es preciso hacer una aclaración previa sobre la cronología de este trabajo, pues se centra en el período que va desde el inicio del reinado de Felipe IV hasta 1675. Ese marco temporal responde a dos motivos. Por un lado, 1621 es un año muy importante para analizar dentro del siglo XVII la evolución del crédito ${ }^{9}$. Hay una política del gasto distinta a la del reinado anterior, mucho más ambiciosa a causa de la guerra, cuyos problemas financieros van a ser resueltos optando por soluciones innovadoras. Por otro lado, el comportamiento de los metales preciosos que aquí tratamos no se circunscribe a un período rígido, sino que la dinámica real traspasa la cronología de los reinados, prolongándose en el tiempo. Lo que aquí tratamos no es una cuestión política, sino económica, y, por lo tanto, tiene su propio ritmo. Habríamos deseado que este estudio llegase hasta el final del reinado de Carlos II, pero resulta imposible por las limitaciones que ofrecen las fuentes a partir de 1675 a la hora de elaborar una serie estadística homogénea. Sólo es posible utilizar cantidades globales fiables hasta esa fecha. Las dificultades que encontramos a partir de entonces a la hora de manejar las cifras nos llevarían a explicaciones que exceden la extensión y finalidad de estas páginas.

Los intentos por cuantificar las remesas americanas han puesto de manifiesto las limitaciones de las fuentes oficiales a la hora de ofrecer cifras reales sobre el comportamiento de los fondos privados. La libertad para registrar o no los metales preciosos de carácter privado durante el reinado de Carlos II las invalida para emprender cualquier estudio cuantitativo. En cualquier caso, las limitaciones de esa fuente eran ya una realidad muchos años antes de que legalmente se diese libertad a la transferencia de fondos. El fraude distorsionaba cualquier intento por

\footnotetext{
${ }^{9}$ Álvarez Nogal (1997).
} 
controlar las remesas de carácter privado. Ahora bien, si en lugar de preocuparnos del volumen global de metales preciosos importados queremos saber el volumen llegado para la Real Hacienda, las fuentes oficiales pueden ser un valioso instrumento para alcanzar ese objetivo, siempre y cuando, antes de aceptar las cifras que nos muestran en primera instancia, se sepa matizar y corregir las deficiencias más importantes de ese tipo de documento.

\section{LAS RELACIONES SUMARIAS COMO FUENTE PARA CUANTIFICAR LOS FONDOS PÚBLICOS}

De los muchos tipos de informes oficiales de que disponemos para cuantificar los metales preciosos que llegaron a España registrados en las flotas, uno de los más interesantes es, sin duda, la relación sumaria (tablas 1, 2,3 y 4) ${ }^{10}$. Se trata de una relación elaborada por los oficiales reales de la Casa de la Contratación a partir de los libros registro de los navíos, con el objeto de informar inmediatamente al rey del valor y la propiedad de los metales preciosos llegados en una flota ${ }^{11}$. El encabezamiento de este documento es siempre el mismo: «Relación de las partidas de oro, plata y reales que para Su Majestad y particulares se han traído registradas...»

Se pueden diferenciar dos tipos distintos en función de su contenido. Uno particular para cada barco y otro general para el volumen total registrado en la flota. La relación sumaria particular recoge todas y cada una de las partidas que venían registradas en cada navío, especificando su propietario y el valor de esa suma en pesos ensayados o en pesos de a ocho reales. Este documento no hace una distinción entre caudales

${ }^{10} \mathrm{La}$ tabla 1 ha sido elaborada con las cifras obtenidas de las relaciones sumarias. La fuente de las tablas 2,3 y 4 son las relaciones sumarias corregidas con los datos que especifican las cartas de los oficiales de la Casa de la Contratación al Consejo. Esa documentación se encuentra en el Archivo General de Indias (AGI), Contratación, legs. 2900, 4689-2, 4921 A, 4921 B, 4922, 4923, 4924, 4925, 4926. La tabla 4 al corregir las cifras de particulares no disponemos de datos para algunas flotas, como se deja indicado. Lo cual indica que las cifras totales de los caudales privados en las tablas 2 y 3 aún serían menores y, por lo tanto, mayor la importancia de los fondos públicos.

${ }^{11}$ AGI, Contratación, leg. 5173. Carta de la Casa de la Contratación al Consejo de Indias, 14-4-1629. En la segunda mitad del reinado, cuando las flotas empezaron a llegar habitualmente a Cádiz, la redacción de estos documentos se hizo en esta ciudad y desde allí se enviaban inmediatamente a la Corte. AGI, Contratación, leg. 5177. Carta de la Casa de la Contratación al rey, 4-4-1656. 
públicos y privados porque no tenía esa función; sólo al final se especifican los cuatro conceptos en los que se dividen las remesas: «Su Majestad», «Cruzada», «Donativo» y «Particulares», expresando todas las cantidades en maravedís, la moneda de cuenta usada en la contabilidad castellana. Cuando por cualquier necesidad se dejaba en La Habana o en cualquier otro puerto alguna partida registrada en la relación particular, se especificaba de qué tipo de fondos había sido tomada esa cantidad ${ }^{12}$. La relación sumaria general es simplemente un resumen de las relaciones particulares donde aparece el volumen total de caudales registrados en una flota. De ambos documentos se hacían tres copias, una para el Consejo de Indias, otra para el de Hacienda y la tercera se quedaba como comprobante en la contaduría de la Casa de la Contratación. El envío de esas relaciones iba acompañado de una carta firmada por los tres Jueces Oficiales de la Casa de la Contratación donde se hacían breves comentarios de las cifras llegadas y de otras cuestiones no reflejadas con la suficiente claridad en las relaciones. Ambos documentos reflejaban las mismas cantidades, pero la carta, además de notificar la cuantía, añadía una información muy valiosa a la hora de repartir esos fondos. También se solía informar de las partidas que no estaban disponibles por los gastos propios de la avería o por los pagos ya consignados, cuyas órdenes constaban en la Contaduría de la Casa ${ }^{13}$. Tanto la relación sumaria como el informe de la Casa sirvieron de enlace entre la labor contabilizadora de los oficiales reales de Sevilla y las órdenes de pago que emanaban del Consejo de Hacienda, indicando el destino que debía darse a los metales preciosos que llegaban a su disposición. La información que aportan estos documentos sobre el valor del tesoro llegado para los distintos organismos de carácter público es bastante exacta ${ }^{14}$. Las cifras que manejaba el Consejo de Hacienda constituyen la información más básica en el reparto de los

${ }^{12}$ Esto ocurre sobre todo cuando a partir de 1640 se intensificaron los pagos efectuados en América.

${ }^{13}$ AGI, Indiferente, leg. 1161. Carta de la Casa de la Contratación al Consejo de Indias, 9-7-1635. AGI, Contratación, leg. 4922. Relación elaborada por la Casa de la Contratación dirigida al Consejo de Hacienda, 1635.

${ }^{14}$ García Fuentes (1980, p. 383, cuadro 74 ) señala que a partir de 1665 , durante el reinado de Carlos II, se incrementó la importación de caudales al margen de las flotas, utilizando navíos sueltos. Este autor ha calculado que en la segunda mitad del siglo XvI un 1 por 100 del total de los caudales registrados llegaron en navíos sueltos, de los cuales menos de la mitad pertenecía a la Real Hacienda. Esas cantidades eran tan pequeñas que nunca llegaron a ser tenidas en cuenta dentro de la negociación de los créditos anuales de la Corona. 
metales preciosos ${ }^{15}$. En Madrid se estudiaban minuciosamente las relaciones sumarias para asignar a cada organismo la suma que debía encargarse de distribuir. Un ejemplo de las muchas rectificaciones que sufrían las relaciones sumarias fueron las cantidades de Nueva España llegadas en 1655. Según las relaciones de la Casa, los azogues trajeron para la Real Hacienda 215.940 .970 mrs.; sin embargo, el Consejo de Hacienda contabilizó $223.889 .490 \mathrm{mrs}$. Esta diferencia se debía a que las relaciones sumarias no habían incluido el tejo de oro que venía aplicado al «Bolsillo de su Majestad», ni los $6.000 .000 \mathrm{mrs}$. de las mercaderías. Las cifras de los documentos del Consejo de Hacienda suelen diferir de los elaborados por los oficiales de la Casa de la Contratación. La cuantía total de los fondos en las relaciones sumarias y en los informes del Consejo son quizá las mismas, pero cambia la asignación de su propietario. El total llegado en una formación seguía siendo el mismo en ambos documentos, pero variaba el valor de los distintos conceptos. Mientras en Sevilla se limitaban a relacionar los fondos que llegaban registrados en las flotas, en la Corte se decidía en primera instancia quién debía hacerse cargo de su distribución, en función de su origen. Por ejemplo, una cosa es lo que llegaba registrado de América destinado al arca de bienes de difuntos y otra muy distinta la cantidad que finalmente ingresaba en ese arca. La diferencia solía destinarse a cubrir desde el Consejo de Hacienda las crecientes necesidades financieras de la Corona. Otra cosa muy importante a tener en cuenta es cómo venía registrada esa partida dentro de los cuatro conceptos ya señalados, en los que se dividían los fondos según las relaciones sumarias.

15 Hemos comprobado que las cifras que aporta este documento se repiten después con gran exactitud en las cartas que tratan de la distribución posterior de los caudales. Por ejemplo, en 1621, cuando el Consejo de Hacienda estaba discutiendo el destino del dinero secuestrado a los particulares el año anterior, se indicó que lo llegado bajo este concepto «montaba 2.657.505.594 mrs.», cantidad que coincide, salvo una pequeña diferencia de 10 maravedís (mrs.), con la suma de las relaciones sumarias. AGI, Contratación, leg. 5018. Carta de Miguel de Ipeñarrieta a la Casa de la Contratación, 29-3-1621. Esta misma exactitud la encontramos en la carta dirigida al Presidente del Consejo de Indias en 1626 por el licenciado Baltasar Gilimón de la Mota, que entonces ocupaba la Presidencia del Consejo de Hacienda. En este documento se señala que «lo que a venido para su $\mathrm{Mg}$. en los dichos galeones monta 690.404 ducados», que suponen $258.901 .500 \mathrm{mrs}$., es decir, la misma cantidad que si sumamos el total de «Su Majestad» y «Cruzada» de las relaciones sumarias. AGI, Indiferente, leg. 1149. Carta de Baltasar Gilimón de la Mota a don García de Haro, 10-1-1626. Existe una diferencia de $18 \mathrm{mrs}$. que seguramente fue ignorada al reducir los maravedís a ducados. Cada ducado equivale a $375 \mathrm{mrs}$. 
Cualquier error cometido en Sevilla al elaborar esos informes era detectado de forma inmediata en Madrid, pues las secretarías del Consejo de Hacienda y de Indias comprobaban las cifras con otro tipo de fuentes ${ }^{16}$. Uno de los muchos ejemplos de este modo de proceder sucedió en 1654 . El Consejo de Indias descubrió que en las relaciones sumarias se había duplicado una cantidad e informó al rey de lo siguiente:

«parece que todo este tesoro de su $\mathrm{Mg}$. y bolsas fiscales monta solo 369.928.215 mrs., porque los $9.444 .112 \mathrm{mrs}$. se deben bajar de algunos yerros que se han reconocido en las dichas relaciones que se remitieron a Madrid, de partidas que se duplican en los presupuestos de la cuenta, que consiste en yerros que la Casa de la Contratación embio hechos en las relaciones y sumarios que primero tenia remitidas» ${ }^{17}$.

El interés de la administración real por llevar una contabilidad exacta de las remesas americanas de que disponía le llevó a vigilar cada partida de un modo escrupuloso. Las dimensiones que adquirió el fraude a partir de la segunda mitad del reinado de Felipe IV dificultaron ese control en el caso de los fondos privados, pero esa distorsión no afectó a los de carácter público. Esa preocupación quedó reflejada en la cuantiosa información que actualmente nos permite cuantificar esos fondos. Sin embargo, a la hora de llevar a cabo un estudio de los mismos hay que tener en cuenta que las alteraciones sufridas por la administración en el siglo XVII modificaron los mecanismos de distribución de los caudales públicos llegados en las flotas, haciendo más opaca su expresión en las relaciones sumarias. Por lo tanto, para saber la magnitud de los caudales públicos en el siglo xvn no es suficiente con saber las cantidades que vienen registradas por los tres conceptos fundamentales: «Su Majestad», «Cruzada» y «Donativo», sino que además es necesario tener en cuenta otra serie de partidas al margen de las incluidas en esa clasificación tradicional. A pesar del incremento de las prácticas ilegales, las cifras del rey que señala la documentación oficial siguieron siendo fiables y los responsables de las finanzas reales continuaron realizando sus cálculos presupuestarios sobre ellas. Ahora bien, siendo eso cierto, para valorar

${ }^{16}$ Las cartas de los generales de las flotas no dan una información exacta, porque pretendían informar al rey causando una buena impresión, redondeando cifras. Sin embargo, este tipo de información resulta útil para hacer una estimación de los fondos que venían sin registrar.

17 AGI, Contaduría, leg. 3. Relación y último ajustamiento de los caudales llegados en 1654. Madrid, 17-10-1654. Explica con detalle el error y las cantidades que eran tomadas como válidas. 
correctamente la relación sumaria hay que tener en cuenta dos cuestiones. Por un lado, hay una parte de los metales preciosos públicos que escapan de los registros al generalizarse los pagos oficiales en las cajas americanas ${ }^{18}$. Se trata de una disposición previa a la elaboración de los registros, y, por lo tanto, están excluidos de ese control en las flotas. Al no reflejarse esos fondos, las cantidades de carácter público quedan un poco distorsionadas, pues al fin y al cabo ese dinero debía haber llegado a la Península y, aunque de otra forma, también contribuyó a sostener el gasto de la Monarquía. En segundo lugar, los términos que se emplean para designar la propiedad de los caudales apenas evolucionan dentro del documento, creando una confusión que nos impide contar correctamente los metales preciosos de la Real Hacienda, sobre todo a partir de la década de los años treinta, cuando el término «particulares» resulte totalmente engañoso. En realidad, y como explicaremos más adelante, una parte cada vez más alta de esos fondos, en lugar de pertenecer al comercio, eran propiedad de la Corona.

En cualquier caso, a partir de la década de los años sesenta la elaboración de las relaciones sumarias sufrió un gran deterioro, motivado en parte por la crisis que atravesó el funcionamiento de la administración real. Esta inestable situación complicó el medir correctamente las cantidades disponibles, porque no se respetaban ya los anteriores criterios de clasificación, ni llegó a consolidarse ningún otro sistema lo suficientemente claro a la hora de establecer el origen de ese dinero.

Por otra parte, entre 1640 y 1665 la Real Hacienda efectuó pagos en las propias flotas después de haberse cerrado el registro, y esa disposición anticipada quedó reflejada en las relaciones sumarias, permitiendo una distinción entre lo que inicialmente se había registrado y lo que finalmente se había recibido (tablas 2 y 3$)^{19}$. A partir de 1665 la documentación no especifica los pagos anticipados, pero al no aparecer la cantidad que llegaba para la Real Hacienda en algunas flotas se da a entender que esa suma se ha entregado previamente en América ${ }^{20}$. A medida que avanzamos en el siglo xvir, la información se diluye en un conjunto de documentos precariamente redactados, en los que es frecuente encontrar vacíos documentales, sin que sea posible explicar el motivo.

${ }^{18}$ Hemos podido comprobar el aumento de los pagos efectuados en América a medida que trascurre el reinado de Felipe IV. Álvarez Nogal (1997a).

19 AGI, Contratación, leg. 4922.

20 Para los años 1667,1670 y 1673 la relación sumaria no recoge la cifra de «Su Majestad», $y$, sin embargo, viene reseñada la cantidad registrada para «Cruzada» y «Donativo». 
Según las relaciones sumarias, durante el reinado de Felipe IV inicialmente se registró en las flotas un total de $57.654 .556 .406 \mathrm{mrs} .{ }^{21}$, una media anual de $1.310 .330 .827 \mathrm{mrs}$. (tabla 1). Lógicamente el ritmo de llegada no fue uniforme. Se pueden diferenciar al menos tres períodos. Entre 1621 y 1630 la media se puede comparar con el período más rico, 1596-1600, con algo más de 2.500 millones de maravedís al año. En cambio, entre 1631 y 1650 cayó a los niveles de la primera mitad del reinado de Felipe II, en los que no se superaban los 1.500 millones anuales, con una lenta tendencia a descender. En la etapa final, de 1650 a 1665, los ingresos se redujeron drásticamente, sin sobrepasar los 500 millones de media anual. Del monto total del registro, un 19,5 por 100 pertenecía a «Su Majestad», el 5,1 por 100 a la «Cruzada» y el 0,5 por 100 se recaudó por concepto de «Donativo».

\section{3. ¿A QUÉ LLAMAMOS CAUDALES PÚBLICOS?}

Las partidas de carácter público, de cuya distribución se encargaba la Real Hacienda, venían registradas en las flotas con los nombres de «Su Majestad», «Cruzada» y «Donativo». Hamilton también adoptó este criterio a la hora de presentar los resultados de su cuantificación, y desde entonces esta clasificación ha sido aceptada prácticamente sin discusión ${ }^{22}$. No se trata de un criterio arbitrario. Existen referencias documentales, donde los oficiales reales consideran caudales de la Real Hacienda la suma de esos tres conceptos ${ }^{23}$. Esa distinción obedece al origen de los fondos y determina el órgano de gobierno que debía encargarse de su distribución. Es necesario definir lo mejor posible el significado de cada uno de los nombres para comprender mejor la función que tenía asignada cada una

${ }^{21}$ Álvarez Nogal (1995). Esa cifra supone 153.745.848 ducados. La Real Hacienda y sus oficiales utilizaban tanto los maravedís como los ducados como unidades de cuenta para expresar el valor del tesoro llegado en las flotas. El maravedí porque era la unidad de cuenta por excelencia dentro de cualquier operación contable, y el ducado porque, además de permitir manejar cifras más reducidas, era la unidad de referencia en los negocios del rey con sus banqueros.

${ }_{22}$ Hamilton (1948), p. 47; García Fuentes (1980), p. 385; Vilar (1972), p. 198.

${ }^{23}$ En un resumen encargado por don Antonio de Camporredondo y Río, Gobernador del Consejo de Hacienda, a la Casa de la Contratación, las cantidades de «Su Majestad» se suman a las de «Cruzada» y «Donativo». Además, esa cifra coincide, salvo pequeñas diferencias, con los datos de las relaciones sumarias (tabla 1). Esta relación se encuentra en AGI, Contratación, leg. 4921B. «Relación de lo que monta la plata, oro y reales que para su Majestad y particulares ha traído de las Indias en las armadas y flotas que han llegado destos reinos desde el año de 1621 hasta el de 1637», Sevilla, 8-11-1638. 
de esas sumas. Durante el gobierno de los Austrias, y en especial durante la vailía del Conde-Duque de Olivares, la Monarquía se estructuró en Juntas, cuyo poder no era sólo político, sino también económico. Una forma de salvaguardar la autonomía de cada uno de esos organismos era dotarles de los recursos necesarios para poder ejecutar sus decisiones con independencia, sin tener que depender de otras instancias. Desde el punto de vista de la distribución de los metales preciosos, el Consejo de Hacienda era el órgano más importante a la hora de decidir su aplicación, pero su poder no abarcaba todos los fondos llegados en las flotas.

En principio, de los cuatro conceptos antes señalados únicamente las cantidades registradas bajo el título de «Su Majestad» estaban directamente a disposición del Consejo de Hacienda. Las sumas de «Cruzada» y «Donativo» eran fondos propios de los organismos oficiales que llevaban esos mismos nombres. Sólo una autorización expresa del rey podía permitir al Consejo de Hacienda acceder a esa parte de los caudales americanos. Eso nos lleva a distinguir, dentro de los fondos públicos, entre los que estaban a disposición de ese Consejo para financiar la política de la Monarquía y los que, a través de las distintas Juntas, cubrían gastos y compromisos de muy diversa índole. Aunque todo ese dinero era de carácter público tenía dueños muy diferentes.

Las cantidades registradas bajo el título «Su Majestad» recogían los ingresos que la Corona percibía en América por distintos conceptos fiscales, siendo el más importante de todos ellos el quinto real.

Los ingresos de «Cruzada» se recaudaban en América desde 1523, vendiendo indulgencias papales a todos los que sufragaban económicamente la lucha contra el infiel. Aunque al principio se percibía de forma esporádica, con el tiempo llegó a convertirse en uno de los ingresos más importantes ${ }^{24}$. A mediados del siglo xvI Castilla solía recaudar en la Península por este concepto una media de 800.000 ducados de plata al año ${ }^{25}$. La cantidad procedente de América nunca alcanzó esa cifra, pero se incrementó en un 32,5 por 100 con respecto al siglo XV. Entre 1621 y 1665 llegó a España para la Cruzada un total de $2.955 .486 .340 \mathrm{mrs}$. Esta cifra suponía un 5,1 por 100 del total de las remesas importadas en los galeones en el reinado de Felipe IV, mientras que durante el reinado

${ }^{24}$ En el reinado de Felipe II la bula de la Santa Cruzada no se predicó con continuidad, pues fue suspendida por Paulo IV en 1556, para volverse a implantar a partir de 1573 de modo definitivo. Lorenzo Sanz (1979), p. 178.

${ }^{25}$ Dominguez Ortiz (1960), p. 242. 
de Felipe II tan sólo representaba el 1,8 por $100^{26}$. Y siguió creciendo, pues para el periodo de 1650-1700, García Fuentes señala que esta suma suponía un 16 por 100 de los caudales indianos ${ }^{27}$. Ese incremento relativo también se puede observar en el peso que adquirió este concepto dentro de los fondos de carácter público, entre los que pasó de suponer un 8 por 100 a representar el 20 por 100 del dinero de la Real Hacienda. La principal característica de este tipo de caudales es la regularidad de sus cifras brutas, pues la suma que llegó bajo el concepto de «Cruzada» fue casi siempre la misma, al menos hasta 1656.

\section{CUADRO 1}

Cantidades llegadas para la «Cruzada»

(maravedís)

\begin{tabular}{|c|c|c|}
\hline Flota & Relación sumaria & Libro contable \\
\hline 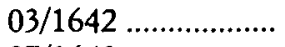 & 44.873 .578 & 45.795 .836 \\
\hline 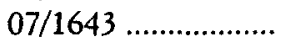 & 105.055 .104 & 105.445 .798 \\
\hline $12 / 1643 \ldots \ldots \ldots \ldots \ldots$ & 91.733 .582 & 93.177 .604 \\
\hline
\end{tabular}

FuENTE: AGI, Contratación, leg. 4923, y Contaduría, leg. 369B.

El ingreso en las arcas de la Casa de la Contratación del dinero de «Cruzada» se contabilizaba junto con el de «Su Majestad», utilizando los mismos libros contables. Sin embargo, el control de su destino final se llevaba al margen, utilizando otros libros. Hemos comprobado que los ingresos anotados en la contabilidad de la Casa por este concepto durante el reinado de Felipe IV prácticamente coinciden con las cifras que nos ofrecen las relaciones sumarias (cuadro 1). Lo cual es una muestra de la fiabilidad de este tipo de fuente para contabilizar algunas partidas controladas por la Administración real. No podemos decir lo mismo si nuestro objetivo fuese cuantificar otras partidas de carácter público, y mucho menos en el caso del dinero de los particulares.

Cuando las necesidades financieras de la Corona alcanzaron tal magnitud que ni siquiera los tremendos esfuerzos fiscales exigidos por el Conde-Duque de Olivares fueron suficientes para atender los compromisos más urgentes se decidió acudir a los donativos, solicitando la generosa

\footnotetext{
${ }^{26}$ Lorenzo Sanz (1979), tomo II, p. 183, para los datos de Felipe II.

${ }^{27}$ García Fuentes (1980), p. 386.
} 
participación de todos los que aún tuviesen fondos disponibles. Este modo de aumentar los ingresos de modo extraordinario no era algo nuevo. Felipe II había solicitado uno en 1590 , pero la particularidad de los decretados por Felipe $\mathrm{IV}$ estuvo precisamente en su frecuencia ${ }^{28}$. El primero del reinado comenzó a pedirse a finales de 1624 y resultó un éxito gracias al ataque inglés que al año siguiente sufrió Cádiz. El espíritu patriótico tuvo en este caso, al igual que en 1640, un protagonismo especial. A partir de 1626 empezaron a llegar en las flotas cantidades procedentes de Indias bajo este concepto, aunque hasta 1629 los oficiales reales no especificaron esa suma como tal en las relaciones sumarias ${ }^{29}$. Tanto en la Península Ibérica como en las posesiones americanas el primer donativo fue el más generoso y fructífero de todos. La administración de esos fondos se encomendó a una Junta especial controlada por Olivares ${ }^{30}$. Tal y como ocurría con el dinero de «Cruzada», una vez llegada la flota, el rey decidía la parte que podía utilizar el Consejo de Hacienda y la que se entregaba a dicha Junta ${ }^{31}$.

\section{EL DINERO DE LA REAL HACIENDA INCLUIDO EN EL REGISTRO DE «PARTICULARES»}

Todos los fondos cuyo origen no encajaba en ninguno de los tres conceptos de carácter público ya señalados venían registrados en las flotas con el genérico nombre de «Particulares». Hamilton definió estas partidas como «las remesas de los emigrantes y los ahorros de los pasajeros que volvían a España» ${ }^{32}$, pues, en su opinión, la mayor parte procedía del signo favorable del comercio español con América. Esta definición puede ser válida para el siglo XVI, cuando una parte importante de los mercaderes

${ }^{28}$ Domínguez Ortiz (1960), p. 279. El capítulo VII de este trabajo aborda este tema, extendiéndose también en el tratamiento de los empréstitos y repartimientos.

${ }^{29}$ AGI, Contratación, leg. 4577. Cédula, 15-1-1627. Archivo General de Simancas (AGS), Consejo y Juntas de Hacienda, leg. 632. Consulta del Consejo de Hacienda, 10-1-1627. En los galeones de ese año llegaron 73.091 .717 mrs. bajo ese concepto, pero incluidos entre las partidas de «Su Majestad».

${ }^{30}$ La Junta de Donativo negoció directamente con los hombres de negocios portugueses, logrando un primer asiento en agosto de 1626 para enviar a Flandes 400.000 escudos de plata. A cambio se les prometieron $26.267 .999 \mathrm{mrs}$. en los fondos que llegaron en noviembre de ese mismo año en la Armada de Tomás de Larraspuru.

${ }^{31}$ Las ventajas que permitía la manipulación de ese metal precioso se concedió a Andrés Hirus, el administrador en España de la compañía «Herederos de Marcos y Cristóbal Fucar». AGI, Contratación, leg. 4577. Cédula, 14-2-1628.

32 Hamilton (1975), p. 45. 
registraba el dinero obtenido al vender sus productos y lo enviaba a la Península en las flotas, pero resulta totalmente anacrónica en el siglo XVII, especialmente a partir de $1650^{33}$. Al aumentar la presión fiscal sobre la Carrera a medida que la tasa de avería evolucionó al alza, y al sucederse tanto los indiscriminados trueques de plata por vellón como las arbitrarias incautaciones de metales preciosos, los comerciantes acabaron refugiándose en las prácticas ilegales a la hora de transferir a España su dinero. Sin embargo, las relaciones sumarias continuaron reflejando la llegada de importantes cantidades bajo el término de «Particulares». Cabe preguntarse entonces a quién le correspondían realmente esos fondos.

La explicación de este hecho responde a que una parte del registro de «Particulares» era dinero que en realidad pertenecía a la Real Hacienda, pero incluso en el caso de los fondos propiamente privados distaban mucho de ser el retorno de los beneficios del comercio, tal y como lo habían podido ser en el pasado ${ }^{34}$. Esta matización supone plantear dos cuestiones. Por una parte, se pierde el significado del término «Particulares» en los registros de las flotas, aunque se siga usando esa palabra para designar una parte del registro, y por otra, desde el punto de vista de la cuantificación, se modifican sustancialmente y al alza los valores que hasta entonces se habían dado a las remesas llegadas para la Real Hacienda. Además del dinero público que llegaba oficialmente registrado fuera de los tradicionales conceptos «públicos», el rey podía ordenar la entrega al Consejo de Hacienda de otras partidas que no eran necesariamente de carácter público.

Así, por ejemplo, de las dos flotas de Nueva España que llegaron a Cádiz en 1636, después de analizar los registros, el rey ordenó a los oficiales de la Casa de la Contratación que agregasen a la Real Hacienda el 94 por 100 de las cantidades llegadas para distintas bolsas fiscales, todas ellas incluidas dentro del registro de «Particulares». Sólo se permitió que del dinero que venía para la construcción de la Armada de Barlovento se empleasen con ese fin 14.000 .000 de mrs. ${ }^{35}$. En 1655, según las relaciones sumarias, de los $223.889 .490 \mathrm{mrs}$. que habían llegado registrados en las naos de azogues inicialmente sólo venían 37.703.824 mrs. para «Su Majestad», pero el Consejo de Hacienda hizo algunas correcciones y logró 59.722 .496 mrs., es decir,

${ }^{33}$ AGI, Contratación, leg. 4926. En 1642 ya se distinguía en los informes dentro del registro de $\alpha$ Particulares» entre particulares comerciantes, no comerciantes y bolsas comunes.

${ }^{34}$ AGI, Contratación, leg. 4926. Relación de los caudales registrados en la Armada de Tierra Firme, 5/1670.

${ }^{35}$ AGI, Contratación, leg. 5021. Cédula del Consejo de Indias, 17-10-1636. 
el 26,6 por 100 de lo llegado. Ese dinero aún era insuficiente y el rey ordenó otras agregaciones de mayor envergadura, con lo que al final pasó a disposición de la Real Hacienda el 67 por 100 de lo llegado ${ }^{36}$.

La explicación de estas variaciones está en los fondos de «Particulares». Según el Consejo de Hacienda, la cantidad de dinero privado era sólo de 24.612.134 mrs., incluyendo en ella el valor de las mercaderías. Se trataba de una cantidad casi cinco veces más pequeña de la que indicaban los registros. Si vemos las relaciones sumarias, recogen como particulares 115.796.078 mrs., pero el Consejo de Hacienda rectificó esa cifra dejándola en $18.158 .526 \mathrm{mrs}$. El resto pertenecía a conceptos muy variados (cuadro 2).

\section{CUADRO 2}

Tipo de fondos registrados como «Particulares» en las naos de azogue llegadas en 1655

(maravedís)

\begin{tabular}{|c|c|c|}
\hline Conceptos & Relación sumaria & Informe del Consejo \\
\hline 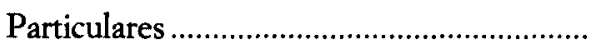 & 115.796 .078 & 18.158 .526 \\
\hline 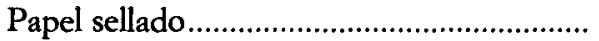 & & 15.915 .366 \\
\hline Media annata de mercedes.............................. & & 26.412 .016 \\
\hline Salarios del Consejo de Indias ..................... & & 10.601 .880 \\
\hline 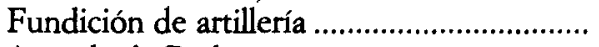 & & 16.756 .832 \\
\hline Armada de Barlovento................................... & & 5.490 .116 \\
\hline 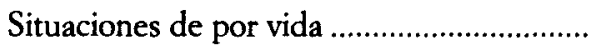 & & 22.018 .672 \\
\hline 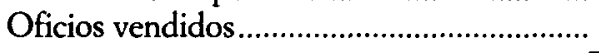 & & 478.574 \\
\hline TOTAL ...... & 115.796 .078 & 115.831 .982 \\
\hline
\end{tabular}

FUENTE: AGI, Contaduría, leg. 570, y AGS, Consejo y Juntas de Hacienda, leg. 1039-1-6-3.

Otro ejemplo son los galeones que arribaron a Santander en 1659. Según las relaciones sumarias sólo venían $187.948 .514 \mathrm{mrs}$.: 72.425 .762 mrs. para «Su Majestad», $111.869 .452 \mathrm{mrs}$. de «Cruzada» y 3.653.300 mrs. de «Donativo». Estas cantidades tan pobres estaban causadas por los pagos que se habían ordenado hacer en América a los

${ }^{36}$ AGS, Consejo y Juntas de Hacienda, leg. 1039-1-6-3. Cuenta del caudal de la Real Hacienda y agregaciones. Madrid, 20-11-1655. Se agregaron a la Real Hacienda las partidas completas llegadas para «Donativo», «papel sellado» y «Bolsillo de su Majestad», el 82 por 100 de «Cruzada» y el 50 por 100 de las partidas de «artilleria» y «media annata». Se respetaron las partidas completas del Consejo de Indias, oficios vendidos y de la Armada de Barlovento. 
maestres de plata. Sin embargo, después de las agregaciones, la Real Hacienda pudo disponer finalmente de un total de $294.092 .781 \mathrm{mrs} .{ }^{37}$

Una de las sumas que habitualmente venía registrada bajo el título de «Particulares» era la cantidad perteneciente a bienes de difuntos. Con el tiempo el número de «bolsas fiscales» incluidas en esta parte del registro se fue ampliando. Así ocurrió con el dinero procedente de las condenaciones del Consejo de Indias, la venta de oficios o los fondos destinados a sufragar el envío de azogue. También solían incluirse en ese ramo el dinero de la Real Hacienda pagado en América, que después cruzaba el Atlántico registrado con el nombre de sus nuevos dueños ${ }^{38}$. A partir de 1632, el incremento de las bolsas fiscales «ocultas», tanto por su número como por su cuantía, obligó a la Casa de la Contratación a ampliar la información complementaria sobre la llegada de caudales, especificando la calidad de este tipo de fondos. Estas noticias se pueden encontrar en las cartas que los Jueces Oficiales de la Casa de la Contratación dirigían al Consejo de Indias. En 1635 los oficiales reales de Sevilla informaron, a través de un escrito explicativo al margen de la relación sumaria, que en el registro de «Particulares» de la Armada de Antonio de Oquendo se incluían 55.534.304 mrs. denunciados por el almirante Alonso de Múxica y $59.620 .134 \mathrm{mrs}$. de orígenes muy diversos, donde estaban incluidas desde las condenaciones del Consejo de Indias hasta partidas procedentes de la renta de esclavos, artillería o novenos de iglesias ${ }^{39}$. Al año siguiente, de los 1.084.034.216 mrs. que habían llegado consignados para particulares, 289.492.928 mrs., casi una tercera parte, pertenecian a la Real Hacienda por distintos conceptos ${ }^{40}$.

Algunos ejemplos muestran esta tendencia con mayor claridad. En julio de 1652 llegaron a Cádiz, al mando de don Pedro de Ursúa y Arismendi, la Armada de la Carrera, la flota de Nueva España y los Azogues. Las tres formaciones traían en total un registro de «Particulares» que, según las relaciones sumarias, era de 541.412 .496 mrs. Después de que la Casa

${ }^{37}$ AGS, Consejo y Juntas de Hacienda, leg. 1095. Último ajustamiento del estado de la Real Hacienda y agregaciones, 21-9-1659. Según la contabilidad de los contadores que asistieron al recibo de la Armada y flota eran $70.260 .656 \mathrm{mrs}$. No se agregó el dinero de todas las bolsas fiscales. De hecho, de la media annata y de los derechos de esclavos se tomó solamente la mitad el resto sirvió para pagar los juros que esta renta tenía situados.

${ }^{38}$ No siempre fue así, pues en algunas ocasiones la Real Hacienda dio permiso a los interesados para que ni siquiera registraran ese dinero.

39 AGI, Indiferente, leg. 1161. Relación del valor de la hacienda..., 8-5-1635. AGI, Indiferente, leg. 1161. Relación de las partidas..., 6-7-1635.

40 AGS, Contadurías Generales, leg. 323. Relación de las cantidades, 1636. AGI, Indiferente, leg. 1165. Carta de la Casa de la Contratación al Consejo de Indias, 11-9-1636. 
de la Contratación ajustase las partidas según sus propietarios, esta cantidad se redujo a $240.335 .594 \mathrm{mrs}$. El resto era propiedad de la Corona ${ }^{41}$. Al año siguiente, en 1653 , de los $313.622 .360 \mathrm{mrs}$. que vinieron registrados sólo $131.711 .980 \mathrm{mrs}$. pertenecían realmente a manos privadas ${ }^{42}$. Por lo tanto, para cuantificar correctamente los fondos públicos no basta con manejar como única fuente la relación sumaria, también es importante la carta de los oficiales reales al Consejo, en la que se valoran con más detalle las cifras recogidas en aquel tipo de documento.

Si estas sumas correspondían al rey, ¿por qué se registraban entonces bajo el nombre de «Particulares» y no bajo el título de «Su Majestad», o bajo otro nombre que expresase claramente su origen y destino? La explicación está relacionada con la crisis que sufrió la Carrera de Indias, y en general toda la Monarquía, a raíz de las crecientes necesidades financieras del reinado de Felipe IV. La Corona se acostumbró a recurrir con excesiva frecuencia a los fondos ajenos para cancelar los créditos comprometidos en las Provisiones Generales con los banqueros extranjeros, cuyas negociaciones estaban en manos del Consejo de Hacienda. Por supuesto, no todos estaban de acuerdo con el destino que se estaba dando a las remesas, especialmente el Consejo de Indias, quien se habia visto muchas veces directamente perjudicado al serle incautados los salarios que tenía consignados en América. Detrás de este modo de actuar subyace el intento de la propia Administración real por excluir una parte de las remesas americanas de los pagos a los hombres de negocios. Se pensaba que quizá, al venir incluidos bajo el nombre de «Particulares», se podía reforzar la inmunidad de esas partidas. A pesar de que esta práctica generaba gran confusión, no se dudó en agregar a los fondos del Consejo de Hacienda las partidas que se consideraba conveniente en un momento de apuro, con independencia del lugar donde apareciesen registradas. En cualquier caso, el Consejo de Hacienda necesitaba un permiso expreso para hacer uso de ellos, y los trámites por los que tenía que pasar podían al final evitar que, si bien no todo, al menos sí una parte de ese dinero cayese en sus manos.

Los fondos más importantes remitidos a la Península bajo el título de «Particulares», pero que en realidad pertenecían a la Real Hacienda, eran el dinero del impuesto de media annata, el papel sellado ${ }^{43}$, los caudales

41 AGI, Contaduría, leg. 570. Relación de la avería, 15-8-1652.

42 AGI, Contaduria, leg. 3, y AGI, Contratación, leg. 4591. Carta de la Casa de la Contratación al Consejo de Indias, 27-8-1653.

43 Martínez de Salinas (1986). 
del Consejo de Indias ${ }^{44}$ y el precio del azogue. Lo recaudado por la media annata de mercedes llegaba a distribución de la Junta que administraba esta renta. Los fondos que enviaba el virrey del Perú para la compra de mercurio eran competencia del Consejo de Indias, pero tanto por su volumen como por su destino tenían entidad propia, y venían al margen de otras sumas que también llegaban aplicadas a dicho Consejo ${ }^{45}$. Esas partidas no deben confundirse con las destinadas a pagar el azogue de Idria, cuya gestión correspondía a los Balbi, una familia genovesa con gran tradición en el mundo financiero. Una parte importante del dinero que pertenecía a la Real Hacienda se entregaba a estos financieros en las cajas americanas. En el asiento que firmaron en 1635 comprometiéndose a suministrar 6.000 quintales de azogue en tres años se negoció el pago en Panamá o en Portobelo ${ }^{46}$. Los Balbi no se fiaban del pago en Sevilla y pidieron la cancelación de esta deuda en Indias para traer esos fondos registrados por su propia cuenta. Pero cuando la Corona vio cómo se reducía su registro por estas disposiciones anticipadas decidió volver a incautar estas cantidades al llegar a Sevilla. Los Balbi se tuvieron que conformar con la promesa de que cobrarían al año siguiente ${ }^{47}$. Sólo entre 1644 y 1649 la Real Hacienda les tomó por este concepto $178.105 .181 \mathrm{mrs}$., más otros 20.000 .000 de mrs. que les incautó la avería para poder despachar los galeones de 1646 .

Junto a éstos llegó más dinero repartido entre un gran número de conceptos de menor importancia y con un carácter más extraordinario. Algunos de los más destacados son los fondos recaudados por la Unión de Armas, los derechos de esclavos, los bienes embargados a franceses en América ${ }^{48}$, o las partidas aplicadas a la fundición de artillería.

En función de todas estas matizaciones podemos obtener tres resultados diferentes, según sea el tratamiento que hagamos de la fuente documental a la hora de cuantificar los fondos públicos, y más concretamente, a la

${ }^{44}$ Entre esos fondos se encuentran los salarios, condenaciones, composiciones, venta de oficios y otras partidas cuya jurisdicción correspondía al Consejo.

${ }^{45}$ Así, por ejemplo, en la flota llegada en noviembre de 1636. De los fondos que llegaron para el Consejo de Indias se agregaron a la Real Hacienda 63.498.984 mrs., en los que se incluían más de 54.000 .000 de mrs. que venían del Perú para pagar los azogues. AGS, Contadurías Generales, leg. 323. Relación de lo que viene para «Su Majestad», «Cruzada» y otros géneros de particulares. Sevilla, 22-11-1636. AGI, Contratación, leg. 4922. Relación y tanteo de la Hacienda de su Majestad.

46 AGS, Contadurías Generales, leg. 130. Copia del asiento con Antonio Balbi, 31-12-1636.

${ }^{47}$ Domínguez Ortiz (1960), p. 118.

${ }^{48}$ Este tipo de fondos estaba a disposición de la Junta de Guerra. 


\section{CUADRO 3}

Variación del porcentaje en la titularidad de las remesas americanas registradas en las flotas, 1626-1675 (\%)

\begin{tabular}{|c|c|c|c|c|c|c|}
\hline \multirow[b]{2}{*}{ Años } & \multicolumn{3}{|c|}{ Caudales privados } & \multicolumn{3}{|c|}{ Caudales públicos } \\
\hline & Real & Rsf & Rsi & Real & Rsf & $R s i$ \\
\hline $1621-1625 \ldots \ldots \ldots \ldots \ldots \ldots$ & 81 & 81 & 81 & 19 & 19 & 19 \\
\hline $1626-1630 \ldots \ldots \ldots \ldots \ldots$ & 81 & 81 & 81 & 19 & 19 & 19 \\
\hline $1631-1635 \ldots \ldots \ldots \ldots \ldots \ldots$ & 70 & 71 & 71 & 30 & 29 & 29 \\
\hline $1636-1640 \ldots \ldots \ldots \ldots \ldots$ & 54 & 70 & 70 & 46 & 30 & 30 \\
\hline $1641-1645 \ldots \ldots \ldots \ldots \ldots \ldots$ & 49 & 66 & 65 & 51 & 34 & 35 \\
\hline 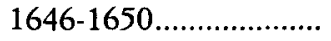 & 74 & 87 & 82 & 26 & 13 & 18 \\
\hline $1651-1655 \ldots \ldots \ldots \ldots \ldots \ldots$ & 57 & 69 & 68 & 43 & 31 & 32 \\
\hline 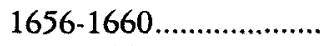 & 51 & 75 & 63 & 49 & 25 & 37 \\
\hline $1661-1665 \ldots \ldots \ldots \ldots \ldots \ldots$ & 59 & 67 & 63 & 41 & 33 & 37 \\
\hline 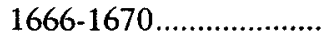 & 20 & 61 & 61 & 80 & 39 & 39 \\
\hline $1671-1675 \ldots \ldots \ldots \ldots \ldots$ & 11 & 62 & 62 & 89 & 38 & 38 \\
\hline
\end{tabular}

FUENTE: Tablas 2 y 3 .

hora de calcular su proporción con respecto al total registrado. El cuadro 3 muestra, para los caudales públicos y privados, y siempre en base a la información ofrecida por las relaciones sumarias, tres tipos de valoraciones distintas según sea el grado de corrección aplicado a las cifras base. La columna denominada «Rsi» (Relación sumaria inicial) recoge las cantidades registradas por los oficiales reales en América, sin tener en cuenta los pagos que se hicieron una vez elaborados los registros. Se trata de disposiciones previas a la llegada de las flotas a la Península. Normalmente esos pagos eran ordenados por el Consejo de Indias a los maestres de plata, los responsables de la custodia de los caudales durante el tiempo que duraba el viaje entre los puertos americanos y la Casa de la Contratación de Sevilla. Teóricamente, no había autorización para usar las remesas americanas hasta que éstas no llegasen al organismo sevillano, pero las dificultades financieras por las que atravesó la Real Hacienda a medida que se deterioró su credibilidad obligaron a aceptar, cada vez con mayor frecuencia, excepciones a este criterio restrictivo. Sin embargo, las relaciones sumarias siguieron siendo elaboradas del mismo modo, con la única excepción de que al final se incluía una breve especificación de los fondos que ya habían sido utilizados. La columna denominada «Rsf» (Relación sumaria final) recoge la verdadera proporción de los fondos públicos y privados después 
de efectuar la rectificación de las cifras ofrecidas por las relaciones sumarias en primera instancia, según esa disposición previa. Como los pagos se efectúan con fondos públicos, los valores de esta columna son inferiores de la «Rsi», pues realmente llega menos dinero para la Real Hacienda de lo señalado en los registros.

La columna con el nombre «Real» es el resultado de una segunda corrección de las fuentes primarias. En ella se refleja con claridad el gran peso que, a partir de 1650, tuvieron los caudales públicos en las flotas, algo que las relaciones sumarias no permiten ver. Esas cifras difieren mucho de los resultados obtenidos para las otras dos columnas, conforme a la verdadera titularidad de los fondos. Las columnas «Rsi» $\mathrm{y}$ «Rsf» reflejan las proporciones entre caudales públicos y privados, tal y como se observan en la documentación, mientras que la columna «Real» nos muestra la verdadera proporción entre ambos tipos de caudales una vez analizado cada uno de los conceptos en los que se agrupaba el dinero. En todos los casos, las cifras totales a las que hacen referencia esas proporciones son las mismas, pero, como se puede observar en el cuadro 3, los resultados son muy diferentes si se tiene en cuenta la limitación de las relaciones sumarias a la hora de indicar la verdadera titularidad de los fondos registrados.

\section{5. ¿CUÁL FUE REALMENTE EL IMPORTE DEL REGISTRO LLEGADO PARA LA REAL HACIENDA?}

A la luz de todo lo señalado hasta ahora resulta necesario reconstruir con la mayor claridad posible el volumen de caudales que recibió la Corona durante el siglo xvn. En las páginas que siguen apuntaremos algunas cuestiones en relación con los problemas más importantes que han impedido hasta ahora una correcta cuantificación ${ }^{49}$.

Según las relaciones sumarias, el caudal público llegado durante el reinado de Felipe IV a disposición de la Real Hacienda representa un 25 por 100 del total registrado. Sin embargo, según muestran los gráficos 1 y 2, existe una gran diferencia entre las flotas llegadas en las primeras décadas del siglo y las de cincuenta años después, corregidas o no las

49 Nos faltan las cantidades de algunas flotas porque en algunos casos no disponemos de las cartas que la Casa de la Contratación enviaba al Consejo de Hacienda especificando la propiedad del registro, o porque, disponiendo de esos documentos, no especifican algunos años las cantidades públicas incluidas en «Particulares». 
cifras que ofrece dicha fuente documental. Las alteraciones que sufrió el registro al extenderse el fraude dieron mayor protagonismo a los caudales de carácter público.

\section{GRÁFICO 1}

Titularidad de los caudales llegados en las flotas entre 1621 y 1625

(Porcentaje «Real»)

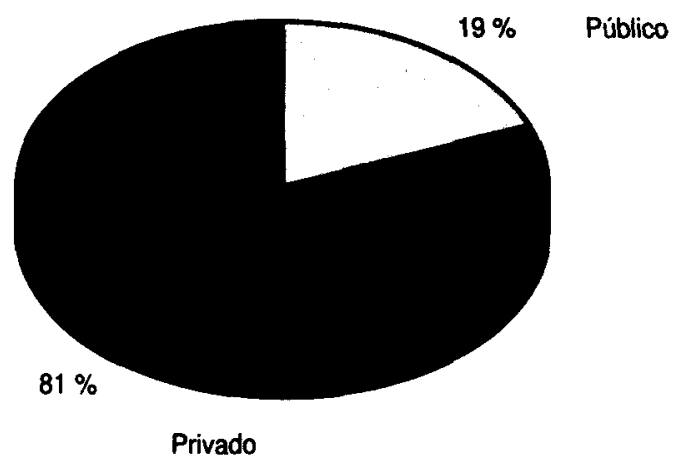

FUENTE: Cuadro 3.

Esas diferencias son más llamativas si vemos los casos particulares de determinadas flotas. El peso que adquirieron los caudales públicos en el reinado de Carlos II recuerda la proporción que tenían los fondos privados al comenzar a reinar Felipe IV. Después de cincuenta años se ha invertido completamente la situación, algo que hasta entonces nunca había ocurrido. El problema de la Real Hacienda no era tanto que llegase menos dinero, sino que el peso del sistema de flotas recaía casi por entero sobre su dinero.

Si hasta entonces lo normal había sido una proporción mayoritaria del dinero de particulares, a partir de 1635 los fondos de la Corona empezaron a ser la parte más importante del registro. Las consecuencias de esta desnivelación en la titularidad de las remesas fueron demasiado duras para una Real Hacienda con pesadas cargas financieras. La avería, el impuesto que sostenía económicamente el sistema de flotas, se cobraba aplicando un porcentaje sobre el valor del registro, y a medida que la proporción de los caudales públicos fue mayor, el sostenimiento de las flotas pasó 


\section{GRÁFICO 2}

Titularidad de los caudales llegados en las flotas entre 1641 y 1645 (Porcentaje «Real»)

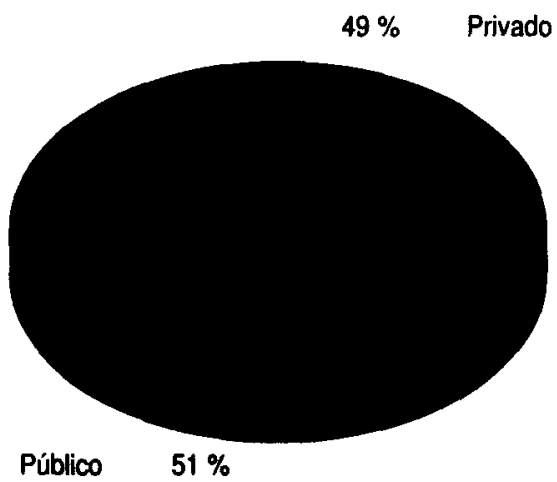

FuENTE: Cuadro 3.

a depender mayoritariamente de la administración real ${ }^{50}$. Si en 1621 la avería era de un 6 por 100 , desde 1628 no bajó nunca del 12 por 100 , y en algunas ocasiones, como en 1647, se aplicó una tasa del 31,25 por $100^{51}$. A partir de 1660 desapareció la obligatoriedad del registro para los particulares, pero la creciente importancia de los fondos públicos no fue sólo fruto del cambio de legislación. Como ya hemos señalado, desde 1635 su porcentaje con respecto a los privados había crecido, independientemente de la evolución de las cantidades brutas (cuadro 3).

La representación gráfica de las cifras absolutas recogidas en las tablas 2 y 3 nos permite analizar la evolución de los caudales según el titular responsable de su disposición. En el caso de las remesas de carácter privado, las líneas «Rsi» y «Rsf» prácticamente coinciden a lo largo de todo el período, porque la disposición anticipada que se hizo del dinero registrado en las flotas afectó sólo a los caudales de «Su Majestad» (gráfico 3). Los

so Álvarez Nogal (1996). De esta pesada carga se daba cuenta el propio rey en una cédula del 18 de marzo de 1634 en la que se decía: «el desorden que se va introduciendo de traerse de las Indias fuera de registro la plata y oro ha llegado a tanto exceso que ya sólo se viene a registrar mi hacienda y la de otras consignaciones particulares que no se pueden excusar, con que viene a cargar sobre mi hacienda el peso de las averías», citado por Dominguez Ortiz (1969), p. 563.

"Serrano Mangas (1989), p. 299. 


\section{GRÁFICO 3}

Evolución de la llegada de caudales de particulares, 1621-1675

(Ducados)

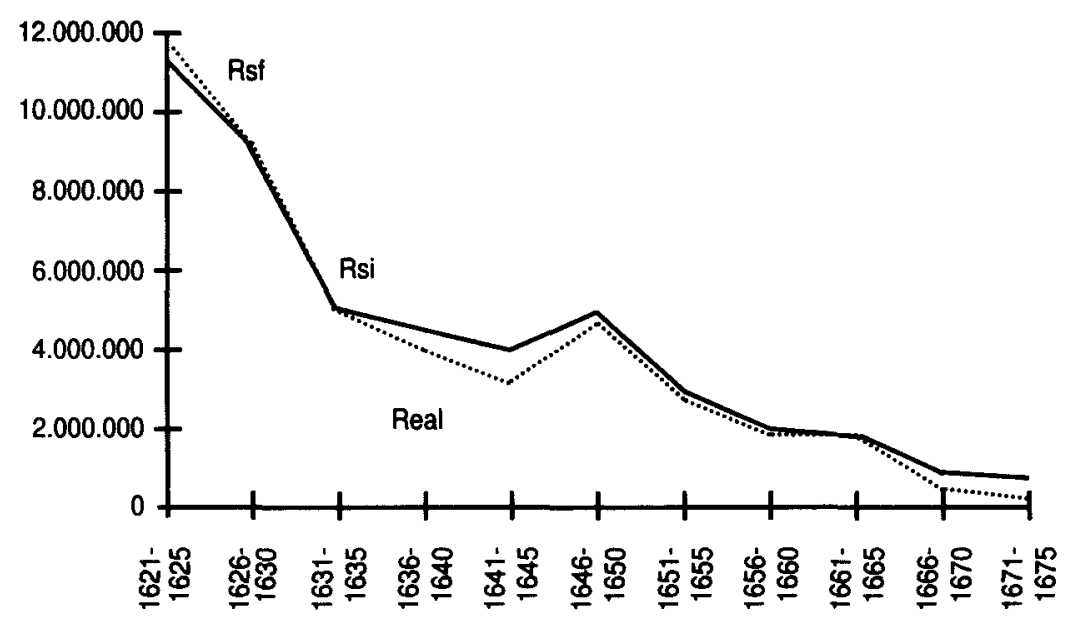

FuENTE: Tabla 3.

maestres de plata no podían disponer de los caudales que iban registrados como «Particulares», aunque, como ya hemos visto, una parte importante de ellos perteneciese también a la Real Hacienda. La distinción entre ambas líneas se establece para indicar una disposición previa que en realidad sólo afectó a los caudales públicos, y por eso los valores de ambas columnas en este caso son los mismos. La línea «Real» nos indica con mayor exactitud el valor del tesoro privado llegado. Esos fondos no eran tanto los resultados del comercio como el fruto de encomiendas o rentas que se pagaban en América, y cuyos beneficiarios no podían eludir el registro sin despertar las sospechas de los oficiales reales, que lógicamente seguían con mucho detenimiento la pista de todo lo que fuese oro y plata. La evolución de la curva en el gráfico 3 muestra cómo el registro de los caudales privados descendió mucho desde 1630 , y esa caída no fue frenada hasta que se decidió respetar seriamente su propiedad.

Entre 1644 y 1655 la Corona hizo un esfuerzo por atraer de nuevo los caudales de particulares hacia el registro. Primero renunciando a hacer más incautaciones y después manteniendo fijo en un 12 por $100 \mathrm{el}$ porcentaje de avería que se debía cobrar a los caudales privados. Esto 
es lo que explica que entre 1646 y 1650 haya una recuperación del porcentaje de los fondos privados con respecto al período anterior (gráfico 3). Pero el secuestro de un millón de ducados a los particulares en la armada del general Martín Carlos de Mencos que llegó en 1649 hundió definitivamente la confianza en el registro, obligando a la Real Hacienda a aplicar de nuevo la tasa real de avería sobre la totalidad del registro sin topes ni excepciones desde $1655^{52}$. Sólo cinco años después se acabó prescindiendo definitivamente del registro obligatorio a la hora de controlar los metales preciosos de carácter privado. El registro obligatorio llegó a considerarse incluso perjudicial en esos momentos, porque gran parte de los fondos privados, en un intento por buscar cauces extraoficiales para llegar a Europa, acabaron en manos extranjeras.

En el fondo, a pesar de las reticencias que hubo para suprimir el registro obligatorio, no se hizo otra cosa que reconocer legalmente lo que de hecho venía ocurriendo. Lo paradójico es que se mantuviese el nombre de «Particulares» en la clasificación de los fondos, a pesar de que se sabía conscientemente que el dinero que venía así registrado tenía una naturaleza muy diferente. Las relaciones sumarias recogen valores muy elevados para lo que realmente era dinero privado, como de hecho se refleja en la tabla 4. Esa tabla muestra la diferencia entre lo que los registros señalan como dinero de particulares y lo que realmente respondía a ese nombre. Hay que tener en cuenta que esas diferencias comienzan a existir a partir de 1635, y que desde esa fecha hasta 1675 siempre existe alguna por pequeña que sea. De los 46 recibos de caudales entre 1633 y 1674, hay 16 casos para los cuales no disponemos de información al respecto, impidiendo efectuar la corrección oportuna. Eso significa que las cifras de caudales públicos aún serían mayores, especialmente entre 1655 y 1665 , que es donde se concentra con mayor intensidad esa falta de información. Esto significa que el descenso de caudales públicos que muestra el gráfico 4 no sería tan pronunciado durante esa etapa.

Tal y como se refleja en el gráfico 4 , la magnitud de las remesas de carácter público es mayor de lo que las fuentes dan a entender a simple vista. A partir de 1631 la disponibilidad de fondos por parte de la Corona

52 El rey emitió una cédula el 7 de junio de 1644 en la que se comprometía a no aplicar un porcentaje superior al 12 por 100 . Pero a esa cantidad había que sumarle después el 1 por 100 de tonelada, el 1 por 100 de flete y el 1,5 por 100 de Balbas. De tal modo que el porcentaje real cobrado era del 15,5 por 100 . Otra cédula del 18 de noviembre de 1655 ordenó cobrar la avería sobre todo el tesoro que llegase, exceptuando sólo las partidas que tenían un privilegio para no pagarla. Antúnez y Acevedo (1797), p. 193. 


\section{GRÁFICO 4}

Evolución de la llegada de caudales públicos, 1621-1675

(Ducados)

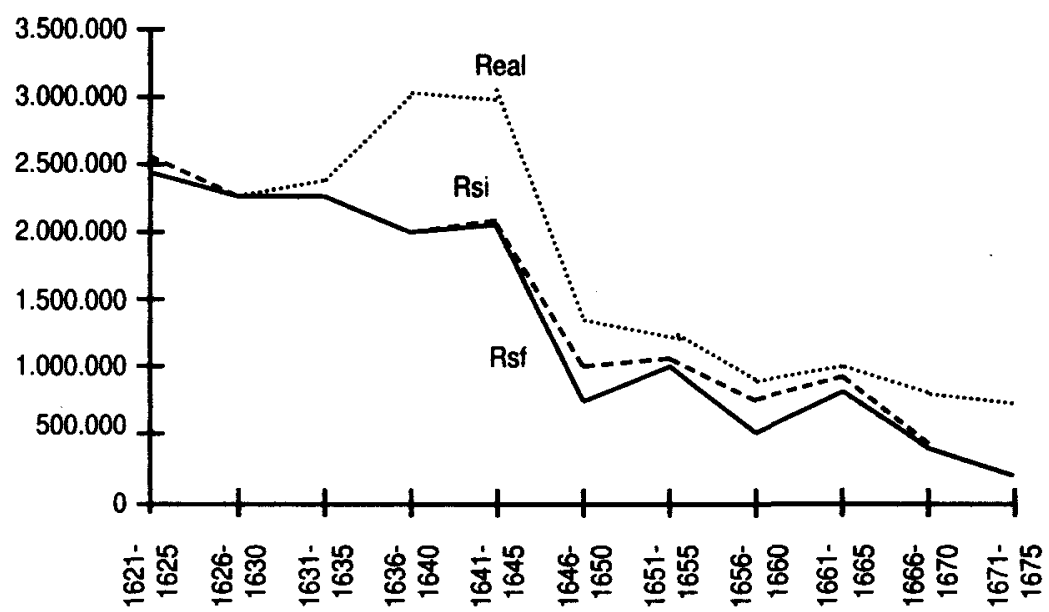

FUENTE: Tabla 2.

es casi un 50 por 100 más de lo que conocíamos a través de las relaciones sumarias (tablas 2, 3 y 4). Los registros sólo muestran un descenso de las cantidades, ocultando el fuerte incremento producido entre 1631 y 1646 en la llegada de fondos públicos. Esta tendencia al alza explica una parte del enorme esfuerzo crediticio que llevó a cabo la Monarquía durante la etapa crucial de la guerra de los treinta años, el comienzo de la guerra con Francia y el estallido de las rebeliones en Cataluña y Portugal a partir de $1640^{53}$. Ese nivel de ingresos en plata redundó en una mayor capacidad de la Real Hacienda para atraerse la confianza de los banqueros extranjeros e incrementar sus préstamos en las Provisiones Generales durante un período tan importante.

La contracción de los fondos recibidos desde 1645 explica el porqué de dos bancarrotas, 1647 y 1652, en tan breve espacio de tiempo. Esas medidas quizá se hubiesen podido retrasar si la caída de ingresos no hubiese sido tan pronunciada. La evolución encaja perfectamente dentro de lo que fue el distinto comportamiento de las finanzas reales tras las suspensiones

\footnotetext{
"33 Álvarez Nogal (1997a).
} 
de pagos de 1627 y 1647. En el primer caso, se incrementa el crédito, los presupuestos anuales de la Corona, y se diversifica el número y la calidad de los agentes que sirven a la Monarquía ${ }^{54}$; en el segundo caso, la bancarrota supone liquidar las relaciones mantenidas con una parte de esos banqueros y reducir la disponibilidad crediticia de la Real Hacienda. $\mathrm{La}$ aplicación de una misma medida tuvo dos consecuencias muy distintas, coincidiendo con una diferente evolución de los fondos americanos. El gráfico 4 muestra la evolución de las cantidades, pero también las diferencias que existen, dependiendo de si corregimos o no las cifras ofrecidas por las relaciones sumarias. Esas diferencias llegan a ser muy elevadas, como también están recogidas en la tabla 2.

\section{CONCLUSIONES}

A lo largo del reinado de Felipe IV se produce un descenso en el volumen de metales preciosos importados de América. Ese proceso venía ya afectando a los caudales privados desde el reinado anterior y se hizo imparable hasta 1641 . La recuperación del registro de particulares en la década de los cuarenta está en relación con los esfuerzos de la Corona por respetar la propiedad de ese dinero cuando llegaba a España, y especialmente con el establecimiento de una tasa fija para el cobro de la avería. A partir de 1649, también como consecuencia del descenso del dinero que venía para la Real Hacienda, fue imposible seguir manteniendo esa política de respeto, y los caudales privados abandonaron definitivamente el sistema de flotas. Cuando en 1660 se suprimió el registro obligatorio no se estaba haciendo otra cosa que ajustar la legislación a la pura realidad. Eso permitía además cobrar la avería en América, liberando de esa pesada carga a lo que seguía llegando para la Real Hacienda. Con respecto a los fondos públicos, éstos se incrementan entre 1626 y 1640. El brusco descenso que se produjo entre 1641 y 1645 contribuyó de algún modo a que en 1647 el Consejo de Hacienda recurriese a publicar un nuevo decreto de bancarrota, acentuando así la crisis financiera del reinado. Sin embargo, a partir de 1656-1660 se logró una mayor estabilidad en los ingresos de la Real Hacienda (gráfico 5).

Por lo tanto, el descenso en la llegada de fondos públicos fue mucho más suave del que hasta ahora se ha venido señalando, lo cual permite

\footnotetext{
${ }^{54}$ Álvarez Nogal (1997b).
} 


\section{GRÁFICO 5}

Evolución real de la llegada de metales preciosos registrados 1621-1675

(Ducados)

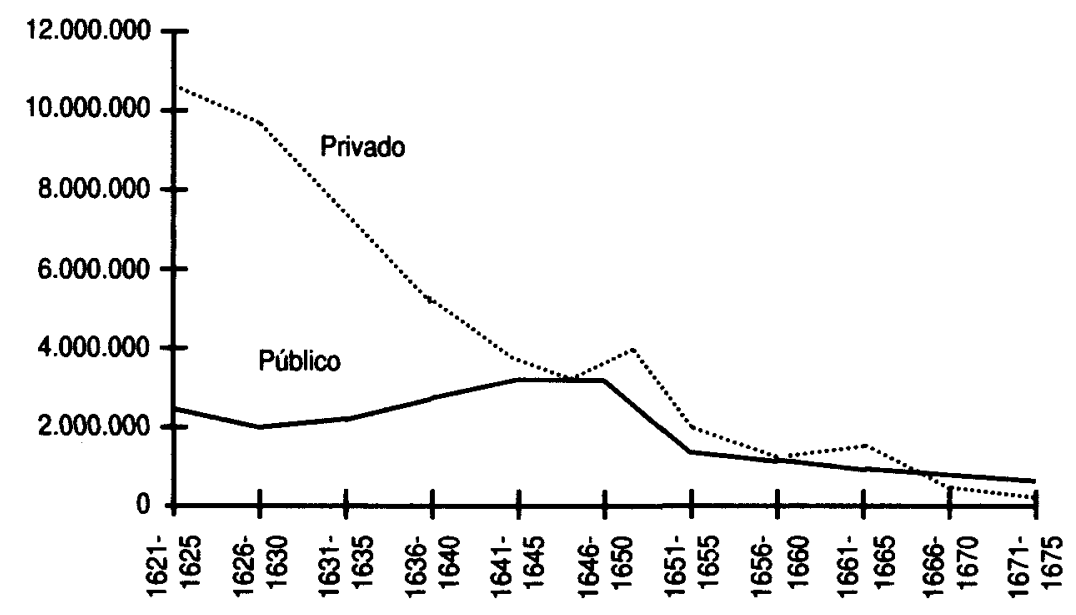

FuENTE: Tablas 2 y 3.

entender mejor el papel que tuvieron las remesas americanas dentro del sistema financiero de la Monarquía Hispánica. Ahora bien, la pregunta que surge a continuación es la siguiente: ¿Se puede trasladar el descenso que muestran los gráficos 3,4 y 5 a la disponibilidad real de caudales de que gozó la Corona? Es decir, la disminución en la llegada de metales preciosos de la Real Hacienda ćrepercutió en la evolución del gasto público o en sus posibilidades de endeudarse? Para responder a esta pregunta aún carecemos del soporte estadístico, pero en nuestra opinión, según se desprende de los resultados de la investigación aquí expuesta, la Corona siguió contando durante el siglo xvII con cantidades de metales preciosos muy importantes, en algunos casos equiparables a las del siglo xv, pero en lugar de servirse de ellas en España, lo hizo con antelación, o bien, en lugar de venir registradas como tales en las flotas, venían ocultas con otro nombre. En cualquier caso, todo ese dinero pertenecía a la Real Hacienda y ésta lo utilizó en su beneficio. Para saber realmente con qué fondos contó la Monarquía en el siglo Xvil a la hora de poner en marcha su política sería necesario sumar a los caudales registrados en las formaciones la disposición realizada en América, el dinero conseguido a 
raíz de los trueques de plata por vellón, los indultos, las condenaciones, los secuestros de particulares ${ }^{55}$ y las contribuciones del Consulado. Teniendo en cuenta la agregación de estas sumas, la cantidad global de las remesas americanas que realmente estuvieron al servicio de los intereses de la Monarquía se incrementa notablemente. Incluso aún más de lo que resultan las cifras oficiales tras aplicar las correcciones señaladas en este trabajo, en el que, en realidad, solamente se han estudiado con detenimiento las limitaciones de ciertas fuentes y el modo de superarlas con objeto de obtener una cuantificación más correcta.

Para calcular la cuantía de los metales preciosos que estuvieron a disposición de la Real Hacienda es necesario dejar a un lado las fuentes que cuantifican la llegada de caudales y abordar ese aspecto desde la perspectiva del gasto, utilizando para ello la rica documentación que afortunadamente se conserva al respecto, especialmente la contabilidad de la Casa de la Contratación. Una cosa es lo que llegaba para el rey según las relaciones sumarias, incluso corregidas, y otra muy distinta es la cantidad global de que dispuso realmente cada año la Real Hacienda para atender los gastos de la Monarquía y sobre la cual descansaba una parte muy importante del crédito.

\section{BIBLIOGRAFÍA}

Álvarez Nogal, C. (1996): «Finanzas y Comercio en la España del siglo xvI: La crisis de la avería», en Actas del VII Congreso de la Asociación Española de Americanistas, Zaragoza (en prensa).

- (1997a): El crédito de la Monarquía Hispánica en el reinado de Felipe IV (16211665), Valladolid.

- (1997b): «Los banqueros de Felipe IV y los metales preciosos americanos (16211665)», Estudios de Historia Económica, núm. 36, Banco de España, Madrid. ANTUNEZZ Y ACEVEDO, R. (1797): Memorias bistóricas sobre la legislación y gobiemo del comercio de los españoles con sus colonias en las Indias Occidentales, (reedición del Instituto de Estudios Fiscales, Madrid, 1981).

BanCora Cañero, C. (1959): «Las remesas de metales preciosos desde El Callao a España en la primera mitad del siglo xvi»», en Revista de Indias, núm. 75, pp. 35-88.

Bernal, A. M. (1993): La financiación de la Carrera de Indias (1492-1824). Dinero $y$ crédito en el comercio colonial español con América, Fundación El Monte, Sevilla.

"La permanente y continua necesidad de dinero para financiar la política imperial determinó que la Corona española recurriese de forma sistemática a las incautaciones de metales preciosos y a los empréstitos forzosos, sobre todo bajo el reinado de Felipe IV. Hampe Martínez (1988) y Lorenzo Sanz (1977). 
- (1997): El coste/beneficio del Imperio, Sesión plenaria del VI Congreso de Historia Económica de España, Girona.

Caracuel Moyano, Rocío (1966): «Los mercaderes del Perú y la financiación de los gastos de la Monarquía, 1605-1700», en Actas y Memorias del XXXVI Congreso Internacional de Americanistas, 1964, vol. IV, Sevilla, pp. 335-343.

CARANDE, Ramón (1965-67): Carlos V y sus banqueros, Madrid.

Chaunu, H. y P. (1955-1960): Seville et l'Atlántique, 1504-1650, París.

Dominguez OrTiz, Antonio (1956): «Los caudales de Indias y la política exterior de Felipe IV», en Anuario de Estudios Americanos, núm. 13, pp. 311-383.

- (1960): Política y Hacienda de Felipe IV, Madrid.

- (1969): «Las remesas de metales preciosos de Indias de 1621 a 1665», en Anuario de Historia Económica y Social, núm. 2, pp. 562-585.

FelloNi, G. (1977) «Asientos, juros y ferias de cambio desde el observatorio genovés, 1541-1675», en I Coloquio Intermacional de Historia Económica, Madrid, pp. 335-360.

FLYNN, D. O. (1980): «La plata hispanoamericana y los mercados mundiales en el siglo xvi», en Moneda y Crédito, núm. 153, pp. 19-48.

GarCía FuENTES, L. (1979): «En torno a la reactivación del comercio indiano en tiempos de Carlos II», en Anuario de Estudios Americanos, vol. XXXVI, pp. 251-286.

- (1980): El comercio español con América (1650-1700), Sevilla.

García-Baquero González, A. (1976): Cádiz y el Atlántico (1717-1778), Sevilla.

- (1996): «Las remesas de metales preciosos americanos en el siglo XVIII: una aritmética controvertida», en Hispania, vol. LVI/1, núm. 192, pp. 203-266.

Garzón Pareja, M. (1980): La Hacienda de Carlos II, Madrid.

HAMILTON, Earl J. (1928): «American Treasure and Andalusian Prices, 1503-1660», en Journal of Economic and Business History.

- (1929): «Wages and Subsistence on Spanish Treasure Ships, 1503-1660», en Joumal of Political Economy.

- (1929): «American Treasure and the Rise of Capitalism, 1500-1700», en Económica.

- (1975): El tesoro americano y la revolución de los precios en España, 1501-1650, Ariel, Barcelona.

Hampe MarTínez, Teodoro (1988): «Oro y moneda de las Indias para el socorro militar de Carlos V, una requisa de 1552», en Boletín Americanista, núm. 38, pp. 151-168.

HaRING, C. H. (1915): «American Gold and Silver Production in the First Half of the Sixteenth Century», en Quarterly Journal of Economics, vol. XXIX, pp. 433-474.

- (1939): Comercio y navegación entre España y las Indias en la época de los Habsburgos, México.

KINDLEBERGER, Charles P. (1988): Historia financiera de Europa, Crítica, Barcelona.

LAIGLESIA, Francisco (1904): «Los caudales de Indias en la primera mitad del siglo XV», en Nuestro Tiempo, pp. 1-29.

LORENZO SANZ, Eufemio (1977): «La requisación de las remesas de oro y plata de mercaderes y particulares por la corona en el siglo xv», en Anuario de Estudios Americanos, vol. XXXIV, marzo, pp. 271-293. 
- (1979): Comercio de España con América en la época de Felipe II, Diputación Provincial de Valladolid.

MaRTín ACOSTA, E. (1992): El dinero americano y la política del Imperio, Madrid. Martínez DE Salinas Alonso, M." Luisa (1986): La implantación del Impuesto del Papel Sellado en Indias, Caracas.

Mathla Tascón, Antonio (1958): Historia de las minas de Almadén, Madrid.

MORINEAU, Michael (1969 y 1970): «Gazzettes hollandaises et tresors americains», en Anuario de Historia Económica y Social, núm. 2, pp. 289.363, y núm. 3, pp. 139-211.

- (1985): Incroyables gazettes et fabuleux métaux. Les retours des trésors américains d'après les gazettes bollandaises XVT.XVIIr siècles, Cambridge-Paris.

Pérez Sindreu, Francisco de Paula (1992): La casa de la moneda de Sevilla. Su bistoria, Sevilla.

Rodríguez Vicente, M. E. (1964): «Los caudales remitidos desde el Perú a España por cuenta de la Real Hacienda. Series estadísticas (1651-1739)», en Anuario de Estudios Americanos, vol. XXI, pp. 1-24.

Ruiz Martín, F. (1970): «La Banca en España hasta 1782», en El Banco de España, Una bistoria Económica, Madrid, pp. 1-196.

- (1990): Las Finanzas de la Monarquia Hispánica en tiempos de Felipe IV (16211665), Madrid,

Ruiz RiverA, J. B. (1977): «Remesas de caudales del Nuevo Reino de Granada en el XVI», en Anuario de Estudios Americanos, vol. XXXIV, pp. 241-270.

Serrano Mangas, F. (1989): Ammadas y Flotas de la Plata (1620-1648), Madrid.

TEPASKE, John J., y KLEIN, Herbert S. (1982): The Royal Treasuries of the Spanish Empire in America, vol. 1, Perú; vol. 2, Upper Peru; vol. 3, Chile y Rio de la Plata, y vol. 4, Ecuador. Durham.

VILAR, Pierre (1964): Crecimiento y desarrollo, Barcelona.

- (1972): Oro y moneda en la Historia, Barcelona. 


\section{TABLA 1}

Metales preciosos llegados a Sevilla en las flotas

según las relaciones sumarias

(maravedís)

\begin{tabular}{|c|c|c|c|c|c|}
\hline Llegada & *Su Majestad» & «Cruzadas & "Donativo» & \&Particulares & Total \\
\hline $11 / 1621$ & 252.470 .160 & 41.665 .272 & 0 & 2.662 .020 .826 & 2.956 .156 .258 \\
\hline $06 / 1623$ & 447.316 .660 & 76.058 .368 & 0 & 2.315 .774 .564 & 2.839 .149 .532 \\
\hline $05 / 1624$ & 691.771 .424 & 63.432 .984 & 0 & 1.909 .819 .698 & 2.665 .024 .106 \\
\hline $10 / 1624$ & 507.598 .064 & 75.997 .248 & 0 & 2.572 .805 .712 & 3.156 .401 .024 \\
\hline $11 / 1625$ & 213.178 .332 & 45.723 .186 & 0 & 992.939 .420 & 1.251 .840 .938 \\
\hline $11 / 1626$ & 607.090 .928 & 122.634 .116 & 0 & 3.090 .310 .460 & 3.820 .035 .504 \\
\hline $11 / 1627$ & 339.666 .562 & 52.122 .494 & 0 & 2.275 .968 .986 & 2.667 .758 .042 \\
\hline $04 / 1629$ & 254.894 .936 & 34.200 .158 & 3.572 .688 & 1.210 .771 .960 & 1.503 .439 .742 \\
\hline $08 / 1630$ & 358.917 .058 & 121.614 .926 & 7.798 .176 & 1.628 .929 .185 & 2.117 .259 .345 \\
\hline $12 / 1630$ & 241.705 .326 & 43.156 .072 & 0 & 869.657 .080 & 1.154 .518 .478 \\
\hline $04 / 1632$ & 279.240 .238 & 38.732 .208 & 1.224 .544 & 927.732 .145 & 1.246 .929 .135 \\
\hline $07 / 1633$ & 484.466 .532 & 92.357 .990 & 0 & 917.891 .842 & 1.494 .716 .364 \\
\hline $02 / 1634$ & 361.919 .942 & 29.638 .088 & 3.536 .000 & 369.982 .612 & 765.076 .642 \\
\hline $06 / 1635$ & 364.903 .668 & 118.620 .300 & 32.567 .662 & 2.256 .989 .294 & 2.773 .080 .924 \\
\hline $12 / 1635$ & 304.719 .246 & 52.901 .864 & 31.414 .174 & 1.000 .479 .904 & 1.389 .515 .188 \\
\hline $08 / 1636$ & 228.087 .232 & 130.763 .456 & 0 & 1.084 .034 .216 & 1.442 .884 .904 \\
\hline $11 / 1636$ & 401.302 .800 & 54.371 .984 & 18.721 .760 & 830.716 .102 & 1.305 .112 .646 \\
\hline $11 / 1637$ & 451.496 .022 & 62.877 .014 & 5.915 .728 & 1.392 .075 .640 & 1.912 .364 .404 \\
\hline $07 / 1639$ & 378.131 .284 & 51.843 .200 & 39.545 .526 & 871.571 .120 & 1.341 .091 .130 \\
\hline $12 / 1639$ & 146.675 .140 & 47.924 .196 & 12.720 .896 & 627.164 .340 & 834.484 .572 \\
\hline $07 / 1641$ & 159.992 .676 & 49.391 .744 & 5.974 .752 & 756.006 .248 & 971.365 .420 \\
\hline $12 / 1641$ & 34.836 .128 & 0 & 610.368 & 212.675 .066 & 248.121 .562 \\
\hline $03 / 1642$ & 255.305 .264 & 44.873 .578 & 1.895 .484 & 522.616 .170 & 824.690 .496 \\
\hline $07 / 1643$ & 94.097 .312 & 105.055 .104 & 17.004 .352 & 258.569 .252 & 474.726 .020 \\
\hline $12 / 1643$ & 781.272 .496 & 91.733 .582 & 12.946 .368 & 562.214 .040 & 1.448 .166 .486 \\
\hline $01 / 1645$ & 52.949 .960 & 45.555 .388 & 234.736 & 1.327 .392 .570 & 1.426 .132 .654 \\
\hline $08 / 1645$ & 228.933 .968 & 54.464 .192 & 5.488 .144 & 293.006 .662 & 581.892 .966 \\
\hline $01 / 1646$ & 90.603 .236 & 32.072 .230 & 0 & 971.289 .914 & 1.093 .965 .380 \\
\hline $04 / 1647$ & 161.688 .904 & 100.861 .166 & 6.427 .520 & 1.015 .460 .920 & 1.284 .438 .510 \\
\hline $09 / 1647$ & 96.402 .043 & 18.138 .048 & 0 & 161.738 .408 & 276.278 .499 \\
\hline $05 / 1648$ & 1.560 .192 & 31.388 .778 & 0 & 1.138 .053 .518 & 1.171 .002 .488 \\
\hline $08 / 1648$ & 11.747 .946 & 71.240 .608 & 0 & 166.866 .356 & 249.854 .910 \\
\hline $09 / 1649$ & 49.121 .039 & 20.451 .952 & 0 & 1.094 .046 .458 & 1.163 .619 .449 \\
\hline $01 / 1651$ & 109.570 .284 & 84.208 .642 & 0 & 986.942 .230 & 1.180 .721 .156 \\
\hline $07 / 1652$ & 204.322 .372 & 178.302 .750 & 37.238 .212 & 541.412 .426 & 961.275 .760 \\
\hline $08 / 1653$ & 14.665 .892 & 59.284 .650 & 698.598 & 235.231 .044 & 309.880 .184 \\
\hline $07 / 1654$ & 102.060 .367 & 105.572 .020 & 2.700 .552 & 385.318 .277 & 595.651 .216 \\
\hline $10 / 1655$ & 37.703 .824 & 62.299 .424 & 141.644 & 115.796 .078 & 215.940 .970 \\
\hline $03 / 1656$ & 1.021 .054 & 642.152 & 505.750 & 260.862 .106 & 263.031 .062 \\
\hline $09 / 1656$ & 98.249 .476 & & & & 98.249 .476 \\
\hline $07 / 1657$ & 31.282 .720 & 45.601 .888 & 6.133 .804 & 173.242 .512 & 256.260 .924 \\
\hline
\end{tabular}




\begin{tabular}{lrrrrr}
\hline Legada & «Su Majestad» & \multicolumn{1}{c}{ «Cruzada» } & «Donativa» & «Particulares» & \multicolumn{1}{c}{ Total } \\
\hline $04 / 1659$ & 72.425 .762 & 111.869 .518 & 3.653 .300 & 675.596 .036 & 863.544 .616 \\
$09 / 1661$ & 312.544 .856 & 81.561 .878 & 15.523 .478 & 527.124 .121 & 936.754 .333 \\
$10 / 1663$ & 0 & 60.015 .816 & 2.751 .180 & 365.222 .256 & 427.989 .252 \\
$12 / 1663$ & 4.688 .010 & 25.850 .336 & 2.774 .400 & 141.376 .488 & 174.689 .234 \\
$01 / 1665$ & 0 & 45.859 .744 & 0 & 85.243 .610 & 131.103 .354 \\
$08 / 1665$ & 3.105 .968 & 56.789 .548 & 1.359 .184 & 122.373 .578 & 183.628 .278 \\
$08 / 1666$ & 20.437 .264 & 50.918 .944 & & 109.578 .974 & 180.935 .182 \\
$09 / 1667$ & & 41.625 .792 & 15.674 .272 & 96.523 .008 & 153.823 .072 \\
$12 / 1667$ & 15.551 .512 & 73.889 .588 & 1.028 .704 & 186.328 .478 & 276.798 .282 \\
$01 / 1669$ & 11.273 .040 & 44.379 .860 & 629.408 & 18.976 .624 & 75.258 .932 \\
$02 / 1670$ & & 30.060 .896 & & 103.552 .984 & 133.613 .880 \\
$05 / 1670$ & 46.629 .042 & 60.871 .664 & 14.192 .960 & 165.554 .792 & 287.248 .458 \\
$08 / 1671$ & 41.725 .153 & 72.595 .712 & 363.936 & 154.724 .752 & 269.409 .553 \\
$09 / 1672$ & 28.290 .176 & 30.353 .024 & & 108.546 .224 & 167.189 .424 \\
$03 / 1673$ & & 15.525 .284 & & 97.211 .016 & 112.736 .300 \\
$10 / 1674$ & 117.671 .008 & 58.179 .612 & 130.016 & 234.961 .488 & 410.942 .124 \\
\hline
\end{tabular}

TABLA 2

Evolución de la llegada de metales preciosos públicos en las flotas y armadas (1621-1675)

(maravedís)

\begin{tabular}{|c|c|c|c|}
\hline Años & $\begin{array}{l}\text { Relación suma } \\
\quad \text { inicial }\end{array}$ & $\begin{array}{l}\text { Relación suma } \\
\text { final }\end{array}$ & $\begin{array}{l}\text { Relación suma } \\
\text { corregida }\end{array}$ \\
\hline $1621-1625 \ldots \ldots \ldots \ldots \ldots \ldots$ & 2.526 .421 .350 & 2.415 .211 .638 & 2.526 .421 .350 \\
\hline $1626-1630 \ldots \ldots \ldots \ldots \ldots . . . . . . . . .$. & 2.187.373.440 & 2.187.373.440 & 2.187 .373 .440 \\
\hline $1631-1635 \ldots$ & 2.196 .242 .456 & 2.196 .242 .456 & 2.305 .656 .344 \\
\hline $1636-1640 \ldots \ldots \ldots \ldots \ldots \ldots$ & 2.035 .816 .238 & 2.030 .376 .238 & 3.139 .785 .776 \\
\hline $1641-1645 \ldots \ldots \ldots \ldots \ldots \ldots$ & 2.079 .335 .596 & 2.042 .615 .596 & 3.079 .522 .988 \\
\hline $1646-1650 \ldots \ldots \ldots \ldots \ldots$ & 999.532 .461 & 691.703 .662 & 1.441 .200 .281 \\
\hline $1651-1655 \ldots \ldots \ldots \ldots \ldots \ldots$ & 1.067 .601 .217 & 998.769 .231 & 1.425 .383 .171 \\
\hline $1656-1660 \ldots \ldots \ldots \ldots \ldots$ & 652.889 .788 & 371.385 .424 & 862.350 .616 \\
\hline 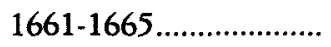 & 745.178 .544 & 612.824 .398 & 809.739 .234 \\
\hline $1666-1670 \ldots \ldots \ldots \ldots \ldots . . . . . . . .$. & 427.162 .946 & 427.162 .946 & 890.356 .676 \\
\hline $1671-1675 \ldots \ldots \ldots \ldots \ldots \ldots$ & 364.833 .921 & 364.833 .921 & 850.049 .011 \\
\hline
\end{tabular}




\section{TABLA 3}

Evolución de la llegada de metales preciosos privados en las flotas y armadas (1621-1675)

(maravedís)

\begin{tabular}{|c|c|c|c|}
\hline Años & $\begin{array}{l}\text { Relación suma } \\
\text { inicial }\end{array}$ & $\begin{array}{l}\text { Relación suma } \\
\text { final }\end{array}$ & $\begin{array}{l}\text { Relación suma } \\
\text { corregida }\end{array}$ \\
\hline $1621-1625 \ldots \ldots \ldots \ldots \ldots$ & 10.705 .249 .782 & 10.453 .360 .220 & 10.705 .249 .782 \\
\hline $1626-1630 \ldots$ & 9.075 .637 .671 & 9.075 .637 .671 & 9.075 .637 .671 \\
\hline $1631-1635 \ldots \ldots \ldots \ldots$ & 5.473 .075 .797 & 5.473 .075 .797 & 5.473 .075 .797 \\
\hline $1636-1640 \ldots \ldots \ldots \ldots \ldots$ & 4.805 .561 .418 & 4.805 .561 .418 & 3.701 .591 .880 \\
\hline $1641-1645 \ldots \ldots \ldots$ & 3.932 .480 .008 & 3.932 .480 .008 & 2.932.292.616 \\
\hline $1646-1650 \ldots \ldots \ldots \ldots$ & 4.547 .455 .574 & 4.547 .455 .574 & 4.105 .787 .754 \\
\hline 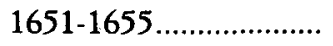 & 2.268 .442 .231 & 2.264 .700 .055 & 1.910 .660 .277 \\
\hline 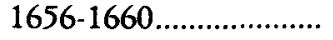 & 1.109 .700 .654 & 1.109 .700 .654 & 900.239 .826 \\
\hline $1661-1665 \ldots \ldots \ldots \ldots \ldots \ldots$ & 1.246 .562 .181 & 1.241 .340 .053 & 1.182 .001 .491 \\
\hline $1666-1670 \ldots \ldots \ldots \ldots$ & 680.514 .860 & 680.514 .860 & 217.321.130 \\
\hline $1671-1675 \ldots \ldots \ldots \ldots \ldots$ & 595.443 .480 & 595.443 .480 & 110.228 .390 \\
\hline
\end{tabular}

\section{TABLA 4}

Metales preciosos de carácter público incluidos en «Particulares» (1621-1675)

(maravedís)

\begin{tabular}{crrr}
\hline Legada de la flota & «Particulares» & «Particulares corregido & \multicolumn{1}{c}{ Diferencia } \\
\hline $07 / 1633$ & 917.891 .842 & 917.891 .842 & 0 \\
$02 / 1634$ & 369.982 .612 & 369.982 .612 & 0 \\
$06 / 1635$ & 2.256 .989 .294 & 2.147 .575 .406 & 109.413 .888 \\
$12 / 1635$ & 1.000 .479 .904 & 1.000 .479 .904 & 0 \\
$08 / 1636$ & 1.084 .034 .216 & 815.186 .424 & 268.847 .792 \\
$11 / 1636$ & 830.716 .102 & 672.211 .524 & 158.504 .578 \\
$11 / 1637$ & 1.392 .075 .640 & 1.128 .207 .840 & 263.867 .800 \\
$07 / 1639$ & 871.571 .120 & 458.821 .752 & 412.749 .368 \\
$12 / 1639$ & 627.164 .340 & 627.164 .340 & No hay datos \\
$07 / 1641$ & 756.006 .248 & 329.459 .350 & 426.546 .898 \\
$12 / 1641$ & 212.675 .066 & 212.675 .066 & No hay datos \\
$03 / 1642$ & 522.616 .170 & 312.633 .562 & 209.982 .608 \\
$07 / 1643$ & 258.569 .252 & 122.366 .884 & 136.202 .368 \\
$12 / 1643$ & 562.214 .040 & 421.926 .906 & 140.287 .134 \\
$01 / 1645$ & 1.327 .392 .570 & 1.240 .224 .186 & 87.168 .384
\end{tabular}




\begin{tabular}{|c|c|c|c|}
\hline Llegada de la flota & «Particulares» & «Particulares» corregido & Diferencia \\
\hline $08 / 1645$ & 293.006 .662 & 293.006 .662 & No hay datos \\
\hline $01 / 1646$ & 971.289 .914 & 861.624 .240 & 109.665 .674 \\
\hline $04 / 1647$ & 1.015 .460 .920 & 869.992 .418 & 145.468 .502 \\
\hline $09 / 1647$ & 161.738 .408 & 161.738 .408 & No hay datos \\
\hline $05 / 1648$ & 1.138 .053 .518 & 1.031 .919 .066 & 106.134 .452 \\
\hline $08 / 1648$ & 166.866 .356 & 166.866 .356 & No hay datos \\
\hline $09 / 1649$ & 1.094 .046 .458 & 1.013 .647 .266 & 80.399 .192 \\
\hline $01 / 1651$ & 986.942 .230 & 871.770 .352 & 115.171 .878 \\
\hline $07 / 1652$ & 541.412 .426 & 470.713 .096 & 70.699 .330 \\
\hline $08 / 1653$ & 238.973 .220 & 185.440 .648 & 53.532 .572 \\
\hline $07 / 1654$ & 385.318 .277 & 360.222 .537 & 25.095 .740 \\
\hline $10 / 1655$ & 115.796 .078 & 22.513 .644 & 93.282 .434 \\
\hline $03 / 1656$ & 260.862 .106 & 260.862 .106 & No hay datos \\
\hline $09 / 1656$ & & 0 & 0 \\
\hline $07 / 1657$ & 173.242 .512 & 173.242 .512 & No hay datos \\
\hline $04 / 1659$ & 675.596 .036 & 466.135 .208 & 209.460 .828 \\
\hline $09 / 1661$ & 527.124 .121 & 527.124 .121 & No hay datos \\
\hline $10 / 1663$ & 365.222 .256 & 365.222 .256 & No hay datos \\
\hline $12 / 1663$ & 141.376 .488 & 141.376 .488 & No hay datos \\
\hline $01 / 1665$ & 90.465 .738 & 25.905 .048 & 64.560 .690 \\
\hline $08 / 1665$ & 122.373 .578 & 122.373 .578 & No hay datos \\
\hline $08 / 1666$ & 109.578 .974 & 37.233 .622 & 72.345 .352 \\
\hline $09 / 1667$ & 96.523 .008 & 20.280 .048 & 76.242 .960 \\
\hline $12 / 1667$ & 186.328 .478 & 57.658 .140 & 128.670 .338 \\
\hline $01 / 1669$ & 18.976 .624 & 554.880 & 18.421 .744 \\
\hline $05 / 1670$ & 165.554 .792 & 63.899 .728 & 101.655 .064 \\
\hline $02 / 1670$ & 103.552 .984 & 37.694 .712 & 65.858 .272 \\
\hline $08 / 1671$ & 154.724 .752 & 20.139 .696 & 134.585 .056 \\
\hline $09 / 1672$ & 108.546 .224 & 10.696 .128 & 97.850 .096 \\
\hline $03 / 1673$ & 97.211 .016 & 56.567 .466 & 40.643 .550 \\
\hline $10 / 1674$ & 234.961 .488 & 22.825 .100 & 212.136 .388 \\
\hline
\end{tabular}

